\title{
Vibrational signatures of curcumin's chelation in copper(II) complexes: An appraisal by IRMPD spectroscopy
}

Cite as: J. Chem. Phys. 150, 165101 (2019); https://doi.org/10.1063/1.5086666

Submitted: 21 December 2018 . Accepted: 02 April 2019 . Published Online: 23 April 2019

Davide Corinti (D), Alessandro Maccelli (D), Barbara Chiavarino (D), Philippe Maitre, Debora Scuderi (D), Enrico Bodo (D), Simonetta Fornarini (iD), and Maria Elisa Crestoni (D)
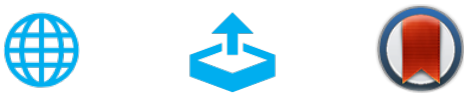

View Online

Export Citatio

\section{ARTICLES YOU MAY BE INTERESTED IN}

Spectra of the $\mathrm{D}_{2} \mathrm{O}$ dimer in the $\mathrm{O}-\mathrm{D}$ fundamental stretch region: Vibrational dependence of tunneling splittings and lifetimes

The Journal of Chemical Physics 150, 164307 (2019); https://doi.org/10.1063/1.5092503

Excited state dynamics of $\mathrm{CH}_{2} \mathrm{I}_{2}$ and $\mathrm{CH}_{2} \mathrm{Brl}$ studied with UV pump VUV probe photoelectron spectroscopy

The Journal of Chemical Physics 150, 174201 (2019); https://doi.org/10.1063/1.5086665

Multistate reversible copolymerization of non-Markovian chains under low conversion conditions

The Journal of Chemical Physics 150, 164903 (2019); https://doi.org/10.1063/1.5088942

The Journal 


\title{
Vibrational signatures of curcumin's chelation in copper(II) complexes: An appraisal by IRMPD spectroscopy
}

\author{
Cite as: J. Chem. Phys. 150, 165101 (2019); doi: 10.1063/1.5086666 \\ Submitted: 21 December 2018 - Accepted: 2 April 2019 • \\ Published Online: 22 April 2019
}

\begin{abstract}
Davide Corinti, ${ }^{1, a)}$ (D) Alessandro Maccelli, ${ }^{1, a)}$ (D) Barbara Chiavarino, ${ }^{1}$ (D) Philippe Maitre, ${ }^{2}$ Debora Scuderi, ${ }^{2}$ Enrico Bodo, ${ }^{3}$ (D) Simonetta Fornarini, ${ }^{,}$(D) and Maria Elisa Crestoni ${ }^{1, b)}$ (D)
\end{abstract}

\begin{abstract}
AFFILIATIONS
1 Dipartimento di Chimica e Tecnologie del Farmaco, Università di Roma "La Sapienza," Piazzale Aldo Moro, 5, I-00185 Roma, Italy ${ }^{2}$ Laboratoire de Chimie Physique (UMR8000), CNRS, Univ. Paris-Sud, Université Paris-Saclay, 91405, Orsay, France

${ }^{3}$ Dipartimento di Chimica, Università di Roma "La Sapienza," Piazzale Aldo Moro, 5, I-00185 Roma, Italy
\end{abstract}

a) Contributions: D. Corinti and A. Maccelli contributed equally to this work.

${ }^{b)}$ Author to whom correspondence should be addressed: mariaelisa.crestoni@uniroma7.it. Tel: +3906 49913596.

Fax: +3906 49913602 .

\begin{abstract}
Curcumin (Cur) is a natural polyphenol with a wide spectrum of biological activities and appealing therapeutic potential. Herein, it has been delivered by electrospray ionization as gaseous protonated species, $[\mathrm{Cur}+\mathrm{H}]^{+}$, and as a $\mathrm{Cu}(\mathrm{II}) \operatorname{complex},[\mathrm{Cu}(\mathrm{Cur}-\mathrm{H})]^{+}$, a promising antioxidant and radical scavenger. The gas phase structures were assayed by infrared multiple photon dissociation (IRMPD) spectroscopy in both the fingerprint $\left(800-2000 \mathrm{~cm}^{-1}\right)$ and hydrogen stretching $\left(3100-3750 \mathrm{~cm}^{-1}\right)$ ranges. Comparison between the experimental features and linear IR spectra of the lowest energy structures computed at the B3LYP/6-311+G(d,p) level reveals that bare $[\mathrm{Cu}(\mathrm{Cur}-\mathrm{H})]^{+}$exists in a fully planar and symmetric arrangement, where the metal interacts with the two oxygens of the syn-enolate functionality of deprotonated Cur and both $\mathrm{OCH}_{3}$ groups are engaged in $\mathrm{H}$-bonding with the ortho $\mathrm{OH}$. The effect of protonation on the energetic and geometric determinants of Cur has been explored as well, revealing that bare $[\mathrm{Cur}+\mathrm{H}]^{+}$may exist as a mixture of two close-lying isomers associated with the most stable binding motifs. The additional proton is bound to either the diketo or the keto-enol configuration of Cur, in a bent or nearly planar arrangement, respectively.
\end{abstract}

Published under license by AIP Publishing. https://doi.org/10.1063/1.5086666

\section{INTRODUCTION}

Curcumin (Cur) is a naturally occurring, polyphenolic yellow pigment found in turmeric. Chemically, Cur corresponds to a bis$\alpha, \beta$-unsaturated $\beta$-diketone of two feruloyl units joined by a methylene group. The $\beta$-diketone moiety is responsible for keto-enol tautomerism in Cur and makes it a Michael acceptor able to react with relevant thiols such as glutathione. For centuries, turmeric has been largely employed as a popular spice in food and as a traditional medicinal herb. Numerous clinical and preclinical studies on Cur and its derivatives (curcuminoids) have revealed multiple beneficial effects, including antioxidant/neuroprotective, ${ }^{1}$ anti-inflammatory, antiseptic, ${ }^{3}$ and antiangiogenic properties.
Recently, promising applications of Cur compounds as a novel drug in the prevention and treatment of cancer ${ }^{5}$ and neurodegenerative diseases such as Alzheimer's dementia (AD) ${ }^{6}$ have emerged in (pre)clinical studies and attracted great attention. The anticancer activity is primarily related to the inhibition and targeting of transcription factor NFKB, cytokines, so inducing antiproliferative and apoptotic effects. The dual hydrophobic and hydrophilic behavior due to the presence of polar groups (an enol group and two phenolic sites) linked by hydrophobic bridges with a set of conjugated bonds bestows Cur the ability to pass the blood-brain barrier, destabilize $\beta$-amyloid fibrils, and strongly bind $\mathrm{Cu}(\mathrm{II})$ and $\mathrm{Zn}$ (II) ions, paving the way for prevention or cure of AD. Restraint of unbalanced concentration of free metals, responsible for inducing oxidative damage 
in neurodegenerative and inflammatory disorders, bears correlation also with the cytoprotective, antiviral, and antirheumatic properties of Cur. In addition, a thoroughly characterized mononuclear $\mathrm{Cu}$ (II)Cur complex has been reported as attractive superoxide dismutase (SOD) mimics, with excellent ability to scavenge free radicals in free cell solution. As a consequence of the metal binding through the keto-enol functionality, the phenolic $\mathrm{OH}$ groups are intact, wherein the $1: 1 \mathrm{Cu}$ (II)-Cur complex retains its therapeutic potential as a free radical scavenger. ${ }^{8}$ However, the limited solubility and fast degradation in water of Cur has led to the development of several formulations to improve its low bioavailability and stability, including complexation with cyclodextrins, ${ }^{9}$ amino acids, ${ }^{10}$ use of absorption factors (e.g., alkaloid piperine) ${ }^{11}$ and of polymeric, ceramic, and liposomal nanoparticles, ${ }^{12}$ conjugation with biopolymers, ${ }^{13}$ and synthesis of new curcumin analogs. 14,1

Curcumin tautomeric equilibrium is influenced by the $\mathrm{pH}$ and the polarity of the solvent, with the $\beta$-diketo group prevailing in acidic or neutral $\mathrm{pH}$, while the hydrogen-bond stabilized keto-enol tautomer is favored in alkaline $\mathrm{pH}$ and nonpolar solvents. In the crystal structure, Cur exists in the keto-enol configuration. In the monoanionic form, Cur ligand and derivatives can be conveniently engaged in binding to a metal ion, particularly iron, ruthenium, copper, and zinc, suggesting the option to employ metalation for enhancing chemical stability, bioavailability, and anticancer activity. ${ }^{16,17}$ Notably, a water-soluble curcumin-modified $\mathrm{Ru}(\mathrm{II})$ arene complex has been recently reported with superior in vitro cytotoxicity and selectivity index in comparison with cisplatin.

Attention has also been focused on the development of Cur complexes of radioactive metals, including Technetium- $99 \mathrm{~m}^{19}$ and Gallium- $68^{20}$ labeled radiopharmaceuticals, as new potential radiotracers for diagnosis of cancer and AD.

Another important treatment modality based on vanadium(iv) complexes of Cur and curcuminoids has been described for photodynamic therapy, showing significant DNA cleavage activity and photocytotoxicity in the visible light of 400-700 $\mathrm{nm}$.

Due to the significant effect that acid/base and metal chelation properties may exert on the biochemical activity of Cur, the present study is aimed to approach the event of protonation and $\mathrm{Cu}$ (II)-curcumin interaction at different binding sites, including the oxygen atoms of the diketo/keto-enol and the phenolic - $\mathrm{OH}$ group on the A or B ring at a molecular level (Scheme 1). To this end, we have examined the intrinsic chemical properties of protonated and copper(II) complexed Cur, $[\mathrm{Cur}+\mathrm{H}]^{+}$and $[\mathrm{Cu}(\mathrm{Cur}-\mathrm{H})]^{+}$, respectively, envisioned as significant intermediates in relevant biomolecular mechanisms.

The sampled ions, prepared in solution and analyzed as bare species, devoid of any external perturbation by electrospray ionization (ESI) mass spectrometry (MS), have been assayed by

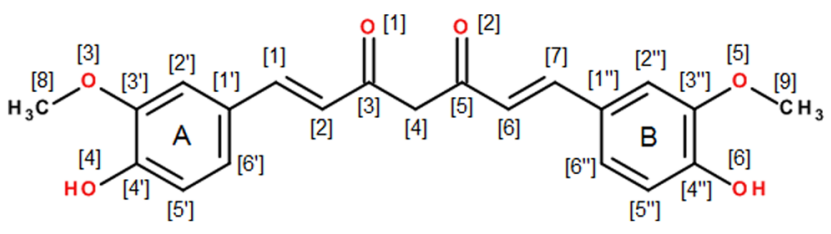

SCHEME 1. Schematic representation of curcumin (in $\beta$ diketo form). collision induced dissociation (CID) experiments and infrared multiple photon dissociation (IRMPD) spectroscopy, in combination with quantum chemical calculations. ${ }^{22-24}$ Based on a photofragmentation process triggered by the sequential absorption of resonant IR photons, ${ }^{25}$ in recent years, IRMPD spectroscopy has become a pivotal tool to shed light on molecular features and binding interactions of a variety of (de)protonated (in)organic ions, ${ }^{26-29}$ metal- and halide-bound adducts of (modified) amino acids and peptides, ${ }^{30-37}$ nucleobases and nucleotides, ${ }^{38-43}$ saccharides, ${ }^{44-46}$ metabolites, ${ }^{47,48}$ and cofactors. ${ }^{49,50}$ This tool is employed here to expand our information on curcumin's scavenging of neurotoxic $\mathrm{Cu}$ (II) metal ions in the prospect to relate direct structural features to biological activity.

\section{EXPERIMENTAL AND THEORETICAL METHODS}

\section{A. Materials}

All reagents used in this work, including curcumin $\left(\mathrm{C}_{21} \mathrm{H}_{20} \mathrm{O}_{6}\right)$, International Union of Pure and Applied Chemists (IUPAC) name (1E,6E)-1,7-bis-(4-hydroxy-3-methoxyphenyl)-1,6-heptadien3,5-dione, also named diferuloylmethane; CAS number 458-37-7), were purchased from Sigma-Aldrich S.r.l. (Milan, Italy) and used as supplied. The ions of interest $[\mathrm{Cur}+\mathrm{H}]^{+}(m / z$ 369) and $[\mathrm{Cu}(\mathrm{Cur}$ $-\mathrm{H})]^{+}(\mathrm{m} / z 430)$ were generated by ESI of a $2 \mu \mathrm{M}$ curcumin and a $4 \mu \mathrm{M}$ curcumin $/ \mathrm{CuSO}_{4}$ (1:3 molar ratio) solution in water/methanol $(1: 1 \mathrm{v} / \mathrm{v})$, respectively. All solutions were directly infused through a fused silica capillary to the ESI source with a syringe pump at a flow

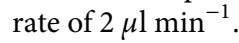

\section{B. MS and IRMPD experiments}

Energy-variable CID experiments were conducted using a commercial hybrid triple quadrupole linear ion trap mass spectrometer (2000 Q TRAP, Applied Biosystems), with a Q1q2QLiT configuration (Q1, first mass analyzing quadrupole; q2, nitrogen-filled collision cell; and $\mathrm{Q}_{\mathrm{LIT}}$, linear ion trap). The electrosprayed ions were desolvated in the first region (Q0), mass selected by Q1, and then allowed to collide with $\mathrm{N}_{2}\left(2.4-4.0 \times 10^{-5} \mathrm{mbar}\right)$ in $\mathrm{q} 2$ at variable collision energies $\left(\mathrm{E}_{\mathrm{lab}}=5-50 \mathrm{~V}\right)$ for CID experiments. The dissociation pattern was monitored by scanning $\mathrm{Q}_{\text {LIT }}$ by using the enhanced mode of operation where the fragments are trapped in QLIT for 35 accumulations in order to increase resolution and signal intensity.

Quantitative threshold information is not directly accessible. ${ }^{51}$ However, for comparative purposes among competitive dissociation pathways, phenomenological threshold energies (TE) for various fragmentation channels may be derived from linear extrapolation of the rise of breakdown curves obtained by converting the collision energies to the center-of-mass frame $\mathrm{E}_{\mathrm{CM}}=[\mathrm{m} /(\mathrm{m}+\mathrm{M})] \mathrm{E}_{\mathrm{lab}}$, where $m$ and $M$ are the masses of the collision gas and of the ion, respectively. ${ }^{52,53}$

Each fragmentation channel was confirmed by $\mathrm{MS}^{3}$ experiments carried out on peaks deriving from the first dissociation step.

The IRMPD spectra of mass-selected ions were recorded by using two experimental platforms with different laser sources, while the mass spectrometer units are equipped with an ESI source of similar functioning. The mid-IR range $\left(800-2000 \mathrm{~cm}^{-1}\right)$ has been explored employing the bright IR radiation of a tunable (5-25 $\mu \mathrm{m})$ 
free electron laser (FEL) beamline at the Centre Laser Infrarouge d'Orsay (CLIO) ${ }^{54}$ coupled to a modified hybrid Fourier transform ion-cyclotron resonance (FT-ICR) tandem mass spectrometer (Apex-Qe Bruker Daltonics), equipped with a 7.0 T actively shielded magnet. ${ }^{55}$ The FEL electron energy was set at 42.1 and 44.4 $\mathrm{MeV}$ in two separate runs to obtain a fairly constant laser power of approximately $1 \mathrm{~W}$ in the frequency region of interest. The FEL output delivers $9 \mu \mathrm{s}$ long trains of macropulses at a repetition rate of $25 \mathrm{~Hz}$. Typical macropulse energies were $40 \mathrm{~mJ}$. In this setup, protonated curcumin, $[\mathrm{Cur}+\mathrm{H}]^{+}(\mathrm{m} / z$ 369), was mass selected in the quadrupole mass filter stage and subsequently accumulated in an rf hexapole trap for $1 \mathrm{~s}$, whereas the copper complex, $[\mathrm{Cu}(\mathrm{Cur}-\mathrm{H})]^{+}$ $(\mathrm{m} / z 430)$, was isolated in the ICR cell. All assayed ions were irradiated for 150-500 ms with the IR FEL light, and the photofragmentation products were mass analyzed. In order to reduce saturation of the most pronounced bands, IRMPD spectra of the copper complex were registered by using 2-4 attenuators, each decreasing the irradiation power by a factor of three.

The XH $(\mathrm{X}=\mathrm{C}, \mathrm{N}, \mathrm{O})$ stretching region $\left(3100-3750 \mathrm{~cm}^{-1}\right)$ was investigated using an apparatus assembled at the Università di Roma "La Sapienza," consisting of a tabletop optical parametric oscillator/amplifier (OPO/OPA; LaserVision, Bellevue, WA) laser system whose radiation output is admitted into a modified Paul type quadrupole ion trap mass spectrometer (Esquire 6000+, Bruker Daltonics). ${ }^{56}$ The parametric converter is pumped by a Nd:YAG laser (Continuum Surelite II) operating at $9 \mathrm{~Hz}$ repetition rate and delivering pulses of 4-6 ns duration. The typical output energy of the OPO/OPA was $14-16 \mathrm{~mJ} \mathrm{pulse}^{-1}$ in the investigated spectral range, with a spectral bandwidth of about $3-4 \mathrm{~cm}^{-1}$. In the trap, ions were accumulated for 3-10 ms and then mass-selected prior to being submitted to IR irradiation for $0.5-2 \mathrm{~s}$. The laser wavelength was uniformly changed at a speed of $0.1 \mathrm{~cm}^{-1} \mathrm{~s}^{-1}$.

When the IR light is resonant with an active vibrational mode of the mass-selected ion, the stepwise absorption of multiple IR photons, associated with intramolecular vibrational energy redistribution, can result in an "action spectroscopy" based on a wavelengthdependent photofragmentation process.

IRMPD spectra are therefore collected by recording the photofragmentation yield $\mathrm{R}$, defined as $\mathrm{R}=-\ln \left(\mathrm{I}_{\text {parent }} /\left(\mathrm{I}_{\text {parent }}+\right.\right.$ $\left.\sum \mathrm{I}_{\text {fragments }}\right)$ ), where $\mathrm{I}_{\text {parent }}$ and $\mathrm{I}_{\text {fragments }}$ are the abundances of the parent ion and the fragment ions, respectively, as a function of the laser frequency. ${ }^{57}$ At each selected wavenumber, four mass spectra were recorded and averaged. In all the acquired spectra, a quantitative accord is found between the depletion of the parent ion signal and the rise of the product ion signals.

\section{Computational details}

A conformational search of both $[\mathrm{Cur}+\mathrm{H}]^{+}$and $[\mathrm{Cu}(\mathrm{Cur}-$ $\mathrm{H})]^{+}$ions was run using the Merck molecular force field (MMFF) molecular mechanics model using the Spartan'16 software package. ${ }^{58}$ The lowest energy structures were used as starting geometries for hybrid density functional theory (DFT) calculations. While there is no guarantee that the global minimum will actually be identified, we note that good agreement is found with the curcumin geometries displayed earlier in the literature. ${ }^{59-61}$ Several isomers, envisioned by varying the tautomeric form, either keto-enol or diketo, the site of (de)protonation and copper chelation, have originated sets of conformers differing for bond and torsional angles. In particular, curcumin allows rotation around $\mathrm{C1}^{\prime}-\mathrm{C} 1, \mathrm{C} 7-\mathrm{C} 1{ }^{\prime \prime}, \mathrm{C} 2-\mathrm{C} 3$, and C5-C6 (but also C3-C4/C4-C5 in the neutral diketo form) bonds generating up to 24 rotational conformers.

According to several previously reported studies, the B3LYP functional is able to reproduce adequately the experimental vibrational peaks requiring less computational expense than other methods. In addition, in a recent comparison between B3LYP and MP2, no significant differences in equilibrium geometries and relative energies regarding the closely related $\mathrm{Zn}$ (II)-curcumin complex were found. ${ }^{6}$

This is expected since B3LYP has been shown to provide the same accuracy of MP2 in the determination of vibrational frequencies once a proper scaling factor is applied. ${ }^{62}$ In addition, since the molecule is isolated, and given its bonding pattern, we expect dispersion corrections to play only a minor role. Furthermore, the charge in these systems is fairly localized, and a functional such as B3LYP (which has only a minor portion of Hartree-Fock exchange) is expected to provide an accurate description of the electronic density.

Therefore, the authors have chosen to perform structure optimization and harmonic frequency calculations by using the hybrid density functional B3LYP and the $6-311+G(d, p)$ basis set as implemented in the software suite Spartan'16 (Wavefunction, Inc., Irvine, CA) ${ }^{58}$ thus keeping the computational cost reasonable. However, in the case of $[\mathrm{Cur}+\mathrm{H}]^{+}$, the relative enthalpies and Gibbs free energies have also been obtained by a combination of the single-point MP2 electronic energies with thermal corrections (298 K) from the B3LYP/6-311+G(d,p) calculations. Harmonic vibrational frequency analyses were only performed at the B3LYP/6-311+G(d,p) level to characterize the stationary points as local minima or saddle points and to obtain linear IR spectra and thermodynamic data. The relative energies at $0 \mathrm{~K}$, enthalpies, and Gibbs free energies at $298 \mathrm{~K}$ of the low-lying structures were obtained by applying zero-point and thermal energy corrections.

Mode assignment was attained by comparison of the experimental IRMPD spectra with the calculated IR spectra, scaled by a factor of $0.978(0.958)$ in the fingerprint $[\mathrm{X}-\mathrm{H}(\mathrm{X}=\mathrm{C}, \mathrm{N}, \mathrm{O})$ stretch] region.

A Lorentzian profile, with an associated width (FWHM) of $15 \mathrm{~cm}^{-1}$ in the fingerprint range and $5 \mathrm{~cm}^{-1}$ in the $\mathrm{X}-\mathrm{H}$ stretching range, was adopted for consistency with experimental spectral resolution. In order to investigate the effect of anharmonicity, proton transfer, and finite temperature effects, molecular dynamics (MD) simulations have been performed using the SCC-DFTB semiempirical model. ${ }^{63}$ In particular, we have used the DFTB3 method with the 3ob:freq parameters ${ }^{64,65}$ that includes both a third order expan$\operatorname{sion}^{66}$ and a long-range correction. ${ }^{67}$ The calculations have been performed using the DFTB+ code. ${ }^{6}$

The protonated isolated curcumin molecule was simulated in both the keto and enol forms using, as stating points, two conformers each corresponding to $\mathrm{H}_{\mathrm{K}}{ }_{-}, \mathrm{H}_{\mathrm{K}} \_5$ for the ketonic forms, and to $\mathrm{H}_{\mathrm{E} \_} 1$ and $\mathrm{H}_{\mathrm{E} \_} 5$ for the enolic ones (see Fig. S9). The dynamical interconversion between $\mathrm{H}_{\mathrm{K}} \_1$ and $\mathrm{H}_{\mathrm{K}} 5$ (as well as between $\mathrm{H}_{\mathrm{E} \_} 1$ and $\mathrm{H}_{\mathrm{E} \_}$) ) is forbidden due to the high rotational barriers around the relevant $\mathrm{C}-\mathrm{C}$ bonds which are part of a conjugate system. A short $\mathrm{MD}$ of 5 ps with a Berendsen thermostat has been used to equilibrate the initial structure to $300 \mathrm{~K}$. Then, a constant-energy MD trajectory 
has been propagated for 500 ps for each of the 4 structures. The trajectory time step has been set to $1 \mathrm{fs}$, and a snapshot of the trajectory has been saved every $2 \mathrm{fs}$. Some of the analyses have been performed using the Travis program ${ }^{69}$ and others using "in house" codes.

\section{RESULTS AND DISCUSSION}

\section{A. Photodissociation and CID mass spectra}

Several studies have addressed the characterization of curcumin metal complexes with $\mathrm{Cu}$ (II), $\mathrm{Zn}$ (II), Ga(III), $\mathrm{Al}(\mathrm{III})$, and $\mathrm{Fe}$ (III) using solution and solid state nuclear magnetic resonance (NMR) spectroscopy, mass spectrometry, infrared (IR) and ultraviolet (UV) spectroscopy, cyclic voltammetry, and electron paramagnetic resonance (EPR).

Previous mass spectrometric evidence reported on adducts of amino acids with various heavy metal cations, which were shown to contain the conjugate base of the amino acid. ${ }^{73-75}$ Similarly, when an aqueous methanol solution of curcumin and $\mathrm{CuSO}_{4}(1: 3$ molar ratio) is electrosprayed in the positive ion mode, a prominent adduct identified as $[\mathrm{Cu}(\mathrm{Cur}-\mathrm{H})]^{+}$between copper and deprotonated curcumin is produced, indicative of a significant affinity of $\mathrm{Cu}$ (II) ions for the conjugate base of curcumin. The high resolution mass spectrum of Fig. S1 shows the characteristic pattern of $[\mathrm{Cu}(\mathrm{Cur}-\mathrm{H})]^{+}$, which reflects the natural abundances of $\mathrm{Cu}$ isotopes, and the exact mass of the monoisotopic peak at $m / z 430.04571$. A smaller signal is assigned to protonated curcumin $[\mathrm{Cur}+\mathrm{H}]^{+}$at $\mathrm{m} / z$ 369.13476.

The fragmentation behavior of the $[\mathrm{Cu}(\mathrm{Cur}-\mathrm{H})]^{+}$adduct has been examined by CID at variable energy in a hybrid triple quadrupole linear ion trap mass spectrometer. As evident from Fig. 1, which illustrates the dependence of the relative abundances of precursor and product ions over a range of collision energies reported in the center-of-mass frame $\left(\mathrm{E}_{\mathrm{CM}}\right)$, the fragmentation of $[\mathrm{Cu}(\mathrm{Cur}-\mathrm{H})]^{+}$ion $(\mathrm{m} / z 430)$ occurs along multiple dissociation channels, leading to primary ions at $\mathrm{m} / z 415$, by loss of a methyl radical, $m / z 402$, by elimination of CO, and $m / z 177$, $\left[\mathrm{C}_{10} \mathrm{H}_{9} \mathrm{O}_{3}\right]^{+}$, and by cleavage of the aliphatic chain and release of $\left[\mathrm{C}_{11} \mathrm{H}_{10} \mathrm{O}_{3} \mathrm{Cu}\right]$.

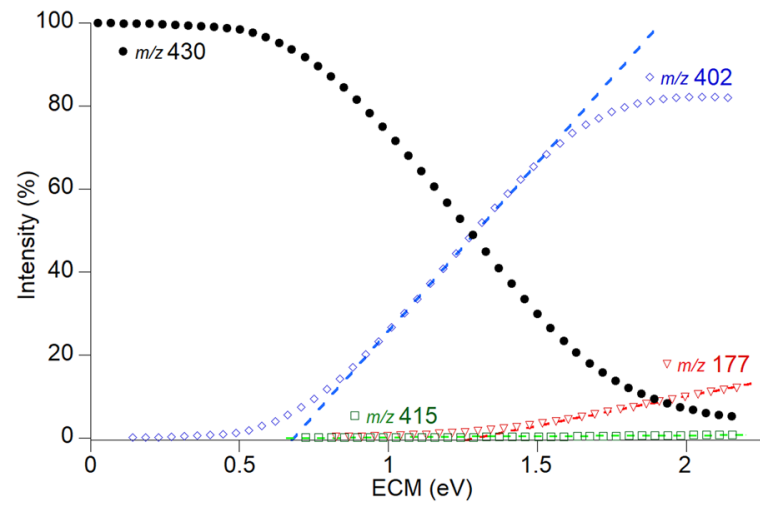

FIG. 1. Relative abundances of mass selected $[\mathrm{Cu}(\mathrm{Cur}-\mathrm{H})]^{+}$ions (black filled cir$\mathrm{cle}, \mathrm{m} / \mathrm{z} 430$ ) and product ions (blue empty diamond, $\mathrm{m} / \mathrm{z} 402$, green open square $\mathrm{m} / \mathrm{z} 415$, and red empty nabla, $\mathrm{m} / \mathrm{z} 177$ ) as a function of collision energy (center of mass) during CID assay.
At higher collision energies, additional fragments appear following the primary loss of $\mathrm{CO}$, as verified by $\mathrm{MS}^{3}$ experiments, namely, ions at $\mathrm{m} / z 212$ and 252 , which in turn yield $\mathrm{m} / z 149$ and 237, and ions at $m / z 371$ and 387. In the energy-dependent CID of $[\mathrm{Cu}(\mathrm{Cur}-\mathrm{H})]^{+}$, the abundances of these secondary products are clustered together with their respective precursor at $m / z 402$ (Fig. 1).

Linear extrapolation of the rise of the breakdown curves provides phenomenological threshold energies (TE) of $0.67 \pm 0.20 \mathrm{eV}$ $\left(64.6 \pm 19 \mathrm{~kJ} \mathrm{~mol}^{-1}\right), 0.71 \pm 0.20 \mathrm{eV}\left(68.4 \pm 19 \mathrm{~kJ} \mathrm{~mol}^{-1}\right)$, and $1.29 \pm$ $0.20 \mathrm{eV}\left(124.3 \pm 19 \mathrm{~kJ} \mathrm{~mol}^{-1}\right)$ for the appearance of $m / z 402,415$, and 177 ions, respectively. This treatment by no means affords a direct, absolute measure of the threshold energy for dissociation; however, it indicates that the dissociation channel prevailing at lower collision energy involves a decarbonylation process.

A comparable fragmentation behavior, with formation of primary fragments at $m / z 415,402$, and 177 , and a similar branching ratio, is also observed when the parent ion $(\mathrm{m} / z$ 430) is assayed by resonant IR excitation to disclose vibrational and structural features by using both the IR-FEL at CLIO $\left(800-2000 \mathrm{~cm}^{-1}\right)$ and the OPO $\backslash$ OPA laser source $\left(3100-3750 \mathrm{~cm}^{-1}\right)$. Figure S2 illustrates exemplary mass spectra of mass-selected $[\mathrm{Cu}(\mathrm{Cur}-\mathrm{H})]^{+}$ions recorded before and after irradiation with the CLIO FEL light tuned at $1550 \mathrm{~cm}^{-1}$.

The dissociation of $[\mathrm{Cu}(\mathrm{Cur}-\mathrm{H})]^{+}$follows the lowest energy path, ${ }^{25}$ which involves CO loss, in agreement with the slow and mild heating provided by the sampled activation methods. According to the $65 \pm 19 \mathrm{~kJ} \mathrm{~mol}^{-1}$ TE value, this fragmentation channel entails the absorption of multiple (more than 3) photons in the $800-2000 \mathrm{~cm}^{-1}$ wavenumber range where the photon energy is $10-24 \mathrm{~kJ} \mathrm{~mol}^{-1}$.

In this mid-IR domain, which includes structurally informative modes, ${ }^{76}$ the spectrum of $[\mathrm{Cu}(\mathrm{Cur}-\mathrm{H})]^{+}$exhibits numerous pronounced absorbances, including the partly resolved couples of bands at 1150 and $1190 \mathrm{~cm}^{-1}$ and at 1505 and $1557 \mathrm{~cm}^{-1}$, the strong absorbance at $1285 \mathrm{~cm}^{-1}$, and a less intense band at $1380 \mathrm{~cm}^{-1}$. Shoulders are observed on the mentioned features at 1230,1437, and $1590 \mathrm{~cm}^{-1}$. Conversely, the higher photon energy range, where the $\mathrm{CH} / \mathrm{NH} / \mathrm{OH}$ stretching transitions can be explored, presents only one intense band in the free $\mathrm{O}-\mathrm{H}$ stretching region at $3569 \mathrm{~cm}^{-1}$ [Fig. 2(a)].

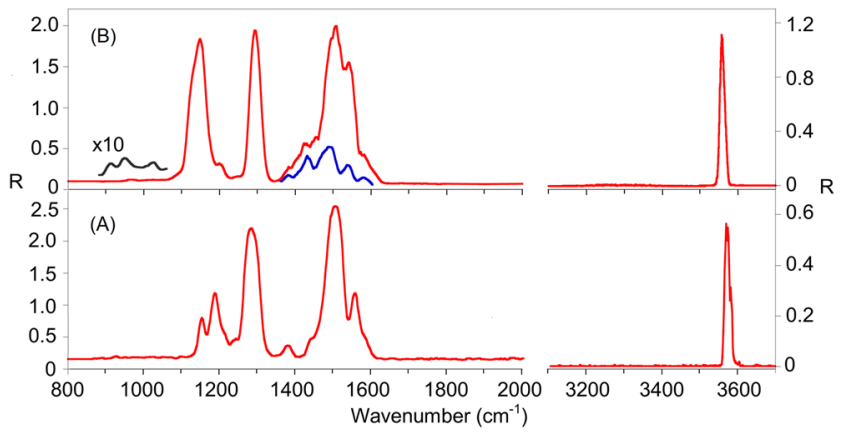

FIG. 2. Experimental IRMPD spectra of mass-selected $[\mathrm{Cu}(\mathrm{Cur}-\mathrm{H})]^{+}$(a) and [Cur $+\mathrm{H}^{+}$(b) ions in the fingerprint and $\mathrm{NH} / \mathrm{OH}$ stretching ranges. The spectral region between 1350 and $1600 \mathrm{~cm}^{-1}$ (blue profile) has also been recorded with an attenuated laser beam $(-3 \mathrm{~dB})$. 
In parallel, free curcumin in its protonated form, $[\mathrm{Cur}+\mathrm{H}]^{+}$, has been assayed to compare the influence of protonation/metalation on the geometric and spectroscopic features of this natural anticancer drug candidate.

The fragmentation of electrosprayed $[\mathrm{Cur}+\mathrm{H}]^{+}$ions at $\mathrm{m} / z$ 369 under both CID at variable energy and resonant IR excitation proceeds by multiple parallel and consecutive channels releasing product ions at $m / z 285,\left[\mathrm{C}_{17} \mathrm{H}_{17} \mathrm{O}_{4}\right]^{+}$by loss of a $84 \mathrm{Da}$ unit, $\left[\mathrm{C}_{4} \mathrm{H}_{4} \mathrm{O}_{2}\right]$, at $m / z 245,\left[\mathrm{C}_{14} \mathrm{H}_{13} \mathrm{O}_{4}\right]^{+}$by elimination of $o$-guaiacol, at $\mathrm{m} / z 177$, feruloyl ion $\left[\mathrm{C}_{10} \mathrm{H}_{9} \mathrm{O}_{3}\right]^{+}$, and at $175,\left[\mathrm{C}_{11} \mathrm{H}_{11} \mathrm{O}_{2}\right]^{+}$, by loss of $\left[\mathrm{C}_{11} \mathrm{H}_{12} \mathrm{O}_{3}\right]$ and $\left[\mathrm{C}_{10} \mathrm{H}_{10} \mathrm{O}_{4}\right]$, respectively. The dependence of the relative abundance of the parent ion and the sum of all fragments as a function of $\mathrm{E}_{\mathrm{CM}}$ is shown in Fig. S3. In-source CID of [Cur $\left.+\mathrm{H}\right]^{+}$ ions performed in the FT-ICR mass spectrometer has allowed the formation of fragment ions and acquiring of high resolution mass spectra, enabling the assignment of their elemental formulas. On this basis, a complete fragmentation scheme obtained by $\mathrm{MS}^{\mathrm{n}}$ experiments is reported in Fig. S4. An exemplary mass spectrum recorded when $[\mathrm{Cur}+\mathrm{H}]^{+}$ions are exposed to IR FEL light tuned at $1490 \mathrm{~cm}^{-1}$ is displayed in Fig. S5.

The IRMPD spectrum of mass-selected $[\mathrm{Cur}+\mathrm{H}]^{+}$ions presented in Fig. 2(b) exhibits evident differences with respect to the one of $[\mathrm{Cu}(\mathrm{Cur}-\mathrm{H})]^{+}[\mathrm{Fig.2(a)}$, although several features appear at similar positions. The major absorptions in the mid-IR region are a rather broad band $\left(\mathrm{FWHM}=54 \mathrm{~cm}^{-1}\right)$ at $1147 \mathrm{~cm}^{-1}$ with a shoulder at $1203 \mathrm{~cm}^{-1}$, a sharper peak at $1294 \mathrm{~cm}^{-1}$, which finds a counterpart in the band at $1285 \mathrm{~cm}^{-1}$ in the IRMPD spectrum of [Cu(Cur $-\mathrm{H})]^{+}$, and an envelope of intense bands, whose (partial) resolution in peaks centered at $1382,1433,1487,1540$, and $1582 \mathrm{~cm}^{-1}$ has been improved by the use of attenuators. In correspondence with this cluster of bands, two strong absorptions appear in the spectrum of $[\mathrm{Cu}(\mathrm{Cur}-\mathrm{H})]^{+}$.

In the NH/OH stretching range, the IRMPD spectrum of [Cur $+\mathrm{H}]^{+}$is dominated by a strong, sharp transition at $3558 \mathrm{~cm}^{-1}$, which matches very closely the one reported at $3569 \mathrm{~cm}^{-1}$ for $[\mathrm{Cu}(\mathrm{Cur}-\mathrm{H})]^{+}$.

\section{B. Computational survey}

\section{Static calculations}

To aid in the interpretation of the observed IRMPD spectrum, which mainly reveals the absorption of the first resonant IR photon, an extensive exploration was undertaken aimed at identifying the most stable structures of $[\mathrm{Cu}(\mathrm{Cur}-\mathrm{H})]^{+}$by computations at the B3LYP/6-311+G(d,p) level of theory. Several potential candidates where the metal may interact either with the $\mathrm{O}$-atoms of the mid diketo/keto-enol moiety or with the O-atoms of the peripheral aryl groups were examined in a number of conformational variants arising from systematic stepwise rotation of the main torsional angles in the skeleton of the curcumin ligand. The most stable structures treated here benefit from the presence of intramolecular hydrogen bond(s) between the ortho phenolic $\mathrm{OH}$ and $\mathrm{OCH}_{3}$ groups. Table IS summarizes the relevant thermodynamic data, including the relative enthalpy $\left(\Delta \mathrm{H}^{\circ}\right.$ rel $)$ and free energy $\left(\Delta \mathrm{G}^{\circ}\right.$ rel $)$ values at $298 \mathrm{~K} \mathrm{~kJ} \mathrm{~mol}^{-1}$. The values of some dihedral angles are listed in Table IIS. Selected structures are presented in Fig. 3 $\left(\mathbf{C u} \_\mathbf{1}, \mathbf{C u} \_\mathbf{1 1}\right)$, while a more extended set is illustrated in Figs. S6 and S7.
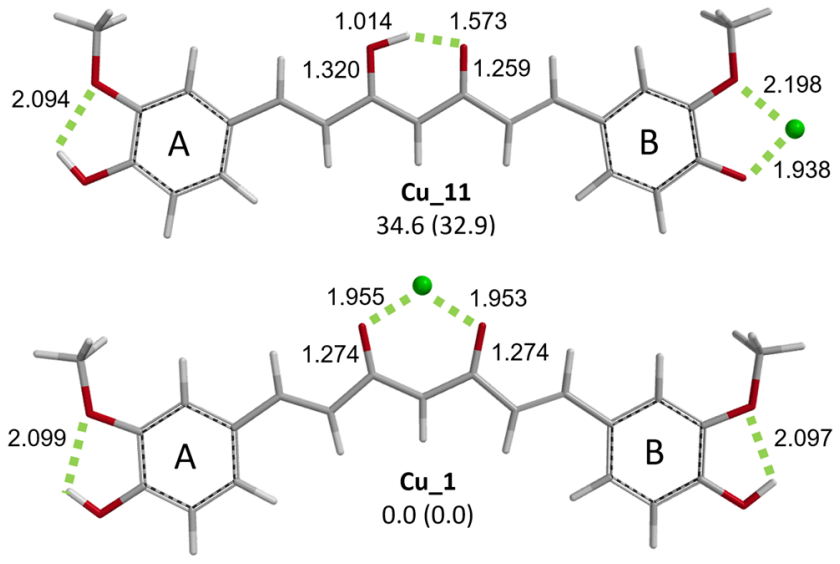

FIG. 3. Optimized geometries of $[\mathrm{Cu}(\mathrm{Cur}-\mathrm{H})]^{+}$structures $\mathrm{Cu} \_1$ and $\mathrm{Cu} \_11 \mathrm{cal}-$ culated at the B3LYP/6-311+G(d,p) level. Relative free energies and enthalpies (in brackets) at the same level of theory at $298 \mathrm{~K}$ are reported in $\mathrm{kJ} \mathrm{mol}^{-1}$. Selected distances are given in $\AA$.

A number of studies have shown that the enol form of curcumin predominates in solution, where the lowest $\mathrm{pKa}$ is assigned to the dissociation of enolic protons.

In agreement with previous reports on curcumin in neutral ${ }^{60,61}$ and transition metal complexes, ${ }^{2}$ our theoretical results confirm that the favored forms for $[\mathrm{Cu}(\mathrm{Cur}-\mathrm{H})]^{+}$complexes may be considered to derive from a deprotonated keto-enol tautomer, resulting in extensive conjugation over the entire ligand.

Three most stable copper-enolate rotational conformers $(\mathbf{C u} \mathbf{1}$, Cu_2, and $\mathbf{C u}$ _3) have been identified, which are included in a $5.5 \mathrm{~kJ}$ $\mathrm{mol}^{-1}$ free energy window. They all arise by coordination of $\mathrm{Cu}(\mathrm{II})$ with the $\mathrm{O}$-atoms of the deprotonated mid diketo/keto-enol moiety and exhibit a planar structure, with a $\angle \mathrm{C} 2 \mathrm{C} 3 \mathrm{C} 4 \mathrm{C} 5$ dihedral angle of ca. $180^{\circ}$ that allows extensive molecular conjugation.

The minimum energy conformer (Cu_1) adopts a fully planar and symmetric arrangement. The metal ion is placed about midway $\left(r_{\mathrm{Cu}} \ldots \mathrm{O}=1.955 \AA\right)$ between the $\mathrm{O}$-atoms, both bearing a charge of -0.787 (natural population analysis). Both $\mathrm{OCH}_{3}$ substituents on the peripheral aryl groups are engaged in $\mathrm{H}$-bonding with the ortho phenolic $\mathrm{OH}\left(r_{\mathrm{CH} 3 \mathrm{O}} \ldots \mathrm{HO}=2.098 \AA\right)$.

All geometries of $\mathbf{C u} \_\mathbf{1 - 3}$ present an extended shape of the alkenyl chain linking the terminal aryl groups differing for the rotation around the $\mathrm{C} 1-\mathrm{Cl}^{\prime}$ (or $\mathrm{Cl}^{\prime \prime}$-C7) whose energy barrier in neutral curcumin has been estimated to be about $30 \mathrm{~kJ} \mathrm{~mol}^{-1}$. ${ }^{59}$ The emerging different orientation of the terminal aryl groups bears, thus, little influence on relative energies. A substantial contribution is instead due to the $\mathrm{CH}_{3} \mathrm{O} \cdots \mathrm{HO}$ hydrogen bond on the aryl groups, which can be estimated by the relative energy of $\mathbf{C u} \_8$, at $22.2 \mathrm{~kJ} \mathrm{~mol}^{-1}$ relative to $\mathbf{C u}$ _1. Isomer $\mathbf{C u} \_\mathbf{8}$ is in everything similar to $\mathbf{C u} \mathbf{1}$, except for a $180^{\circ}$ rotation around one of the $\mathrm{C}-\mathrm{OH}$ bonds, disrupting the $\mathrm{H}$-bond interaction.

Rotation around C2-C3 (and/or C5-C6) results in somewhat folded geometries. When the $180^{\circ}$ rotation involves just one of the two bonds, the so-obtained $\mathbf{C u} \_4, \mathbf{C u} \_5, \mathbf{C u}$-6, and $\mathbf{C u} \mathbf{7}$ rotamers lie at 10.6, 13.4, 14.4, and $14.4 \mathrm{~kJ} \mathrm{~mol}^{-1}$ above $\mathbf{C u}$ _1, respectively. Rotation around both $\mathrm{C} 2-\mathrm{C} 3$ and $\mathrm{C} 5-\mathrm{C} 6$ bonds yields geometries 
such as Cu_9 and Cu_10 even more destabilized, lying at 24.6 and $30.1 \mathrm{~kJ} \mathrm{~mol}^{-1}$, respectively. Copper coordination at a deprotonated phenol site has also been considered, allowing to identify a less stable isomer where $\mathrm{Cu}(\mathrm{II})$ interacts with phenate and methoxyl oxygens, Cu_11, while the rest of the molecule displays an extended planar keto-enolic structure. Another phenate conformer (Cu_12) which resembles $\mathbf{C u} \_2$ arrangement was also investigated, resulting in a slightly less stable structure lying at $36.9 \mathrm{~kJ} \mathrm{~mol}^{-1}$. Cu__1 and the closely related $\mathbf{C u} \mathbf{1 2}$ rotamer are relatively high in energy, though, at 34.6 and $36.9 \mathrm{~kJ} \mathrm{~mol}^{-1}$, respectively.

Notably, the $\mathrm{C}-\mathrm{O}$ bond distances of the two sites sharing the hydrogen bond within the keto $\left(r_{\mathrm{C}-\mathrm{O}}=1.259 \AA\right)$ and enol $\left(r_{\mathrm{C}-\mathrm{OH}}\right.$ $=1.320 \AA$ ) portion of $\mathbf{C u} \mathbf{1 1}$ well agree with those of neutral Cur, which benefits from a similar stabilizing interaction. ${ }^{59}$ These bonds are instead perfectly equivalent $\left(r_{\mathrm{C}-\mathrm{O}}=1.274 \AA\right.$ ) $)$ in $\mathbf{C u} \_\mathbf{1}$ as a consequence of the symmetric chelation with the metal, where charge donation from the ligand and back donation from $\mathrm{Cu}(\mathrm{II})$ are operative.

The significantly lower stability of $\mathbf{C u} \_\mathbf{1 1}$, located at $34.6 \mathrm{~kJ}$ $\mathrm{mol}^{-1}$ above the global minimum, may be related to the lower $\mathrm{pK}_{\mathrm{a}}$ value for the keto-enol group vs phenol deprotonation..$^{70,79}$

Calculations were also performed considering the presence of diketo structures which have been found to exist only in anti-configuration, possibly due to a strong electrostatic repulsion between the two carbonyl groups, at variance with the syn-ketoenol forms stabilized by $\mathrm{H}$-bonding. The lowest energy diketo structure, $\mathbf{C u}$ 13, with a copper-phenate contact, lies at $77.0 \mathrm{~kJ} \mathrm{~mol}^{-1}$ above $\mathbf{C u} \_$, thus discarding any significant contribution to the sampled ion population. A relevant feature of the anti-diketo framework (Cu_13) regards the obvious lack of the stabilizing H-bond of the keto-enol tautomer (e.g., see $\mathbf{C u}$ _12) and a twisted structure, whereby two planar halves adopt a $\angle \bar{C} 3 \mathrm{C} 4 \mathrm{C} 5 \mathrm{C} 6$ dihedral angle of $60^{\circ}$, in sharp contrast with the planar keto-enol forms (e.g., Cu_11 and $\mathbf{C u} \_12$ ) (Table IIS). As a consequence, $\pi$-electron conjugation is distributed over the entire ligand (i.e., dienic and aromatic portions) in the keto-enol form, while it is localized on each half molecule in the diketo structure. ${ }^{60}$

In order to probe the structural changes induced by copper chelation of the deprotonated ligand, a targeted exploration of the conjugate base of Cur, [Cur $-\mathrm{H}]^{-}$, has also been performed at the B3LYP/6-311+G(d,p) level. Isomeric structures for [Cur $-\mathrm{H}]^{-}$ present different deprotonation sites, either the mid diketo/ketoenol group or a hydroxyl group on an aromatic ring. The resulting most stable geometries correspond to phenate isomers because they are stabilized by the hydrogen bond within the keto-enol group. This configuration of free $[\mathrm{Cur}-\mathrm{H}]^{-}$is very different from the arrangement of the $[\mathrm{Cur}-\mathrm{H}]^{-}$ligand forming the chelate $\mathrm{Cu}(\mathrm{II})$ complex, $[\mathrm{Cu}(\mathrm{Cur}-\mathrm{H})]^{+}$.

When deprotonation affects the mid diketo/keto-enol functionality, yielding a structure lying at $109 \mathrm{~kJ} \mathrm{~mol}^{-1}$ relative energy, geometry optimization brings the two keto groups to adopt an antiorientation that likely relieves electrostatic repulsion (Fig. S8). As a whole, comparison with the $[\mathrm{Cur}-\mathrm{H}]^{-}$anion is not expected to aid in the interpretation of the observed $[\mathrm{Cu}(\mathrm{Cur}-\mathrm{H})]^{+}$spectrum, where instead the two oxygen atoms of the syn-enolate group are engaged in $\mathrm{Cu}$ (II) chelation. Thus, it was rather considered that conferring a proton on Cur would impart a positively charged site inducing a folded arrangement in a better simulation of the $[\mathrm{Cu}(\mathrm{Cur}$ $-\mathrm{H})]^{+}$structure.

Therefore, the $[\mathrm{Cur}+\mathrm{H}]^{+}$species has been studied. Different isomers have been examined, deriving from protonation at a carbonyl group in either diketo or keto-enol forms, also conceiving both trans and cis configuration of the dienyl bridge and rotation of the aromatic substituents around the $\mathrm{C}_{\text {aryl }}-\mathrm{C}_{\text {chain }}$ bond (i.e., $\mathrm{C1}^{\prime}-\mathrm{C} 1$ and $\mathrm{Cl}^{\prime \prime}$-C7). All structures are stabilized by the $\mathrm{OH} \cdots \mathrm{OCH}_{3}$ hydrogen bonds on the two aryl groups. The relevant thermodynamic data and dihedral angles are reported in Tables IIIS and IVS, respectively. The most stable structures pertaining to either the diketo or keto-enol forms are shown in Fig. 4, while the remaining ones are displayed in Figs. S9, S10, and S11.

From protonation of the diketo tautomer, a most stable geometry $\left(\mathbf{H}_{\mathbf{K}} \mathbf{1}\right)$ has been obtained and stabilized by an intramolecular hydrogen bond forming a six-membered ring between the charged $\mathrm{C}(\mathrm{O} 1 \mathrm{H})^{+}$site and the carbonyl oxygen $\left(\mathrm{r}_{\mathrm{O} 1 \mathrm{H}^{+}} \ldots\right.$. O2C $\left.=1.447 \AA\right)$. The $\angle \mathrm{C} 3 \mathrm{C} 4 \mathrm{C} 5 \mathrm{C} 6$ dihedral angle equal to $\pm 160^{\circ}$ bestows a moderate bend on $\mathbf{H}_{\mathbf{K}} \mathbf{1}$, which is illustrated in Fig. 4 in the view shown on the right. This is a common trait in all optimized low-lying rotamers involving protonation of the diketo form (see Fig. S9 including $\mathbf{H}_{\mathbf{K} \_} \mathbf{2}, \mathbf{H}_{\mathbf{K}} \_$3, and $\mathbf{H}_{\mathbf{K} \_}$4, lying at 3.2, 3.6, and $4.2 \mathrm{~kJ} \mathrm{~mol}^{-1}$ relative to $\mathbf{H}_{\mathrm{K} \_} \mathbf{1}$, respectively).

In analogy with copper complexes, other diketo-derived species involving rotation around either or both C2-C3 and C5-C6 bonds yield species higher in energy (Table IIIS and Figs. S10 and S11).

Alternatively, protonation at the enol form may be conceived, leading to a family of low-lying rotamers, including $\mathbf{H}_{\mathrm{E} \_\mathbf{1}}, \mathbf{H}_{\mathrm{E} \_} \mathbf{2}$,

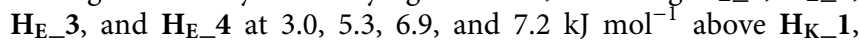
respectively. Common facets to these forms are an intramolecular $\mathrm{H}$ bond at the protonation site $\left(\mathrm{r}_{\mathrm{O} 1 \mathrm{H}^{+}} \ldots \mathrm{O} 2 \mathrm{H}=1.824 \AA\right)$ and a $\angle \mathrm{C} 3 \mathrm{C} 4 \mathrm{C} 5 \mathrm{C} 6$ dihedral angle close to $180^{\circ}$ that allows ring $\mathrm{A}$ and the dienyl chain to be fully coplanar, whereas the $\angle \mathrm{C} 6 \mathrm{C} 7 \mathrm{C}^{\prime \prime} \mathrm{C}^{\prime \prime}$

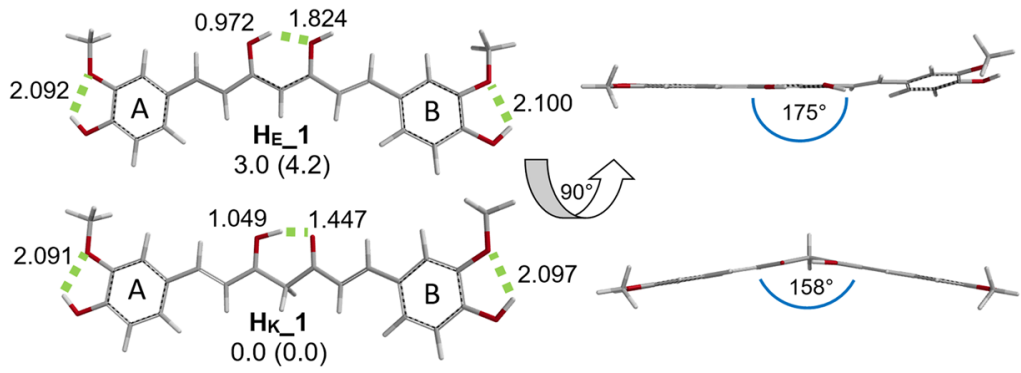

FIG. 4. Optimized geometries of $\left[\mathrm{Cur}+\mathrm{H}^{+}\right.$structures $\mathrm{H}_{\mathrm{K}} 1$ and $H_{E \_} 1$ calculated at the B3LYP/6-311+G(d,p) level. Relative free energies and enthalpies (in brackets) at the same

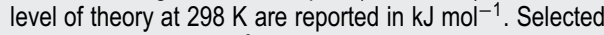
distances are given in $\AA$. 

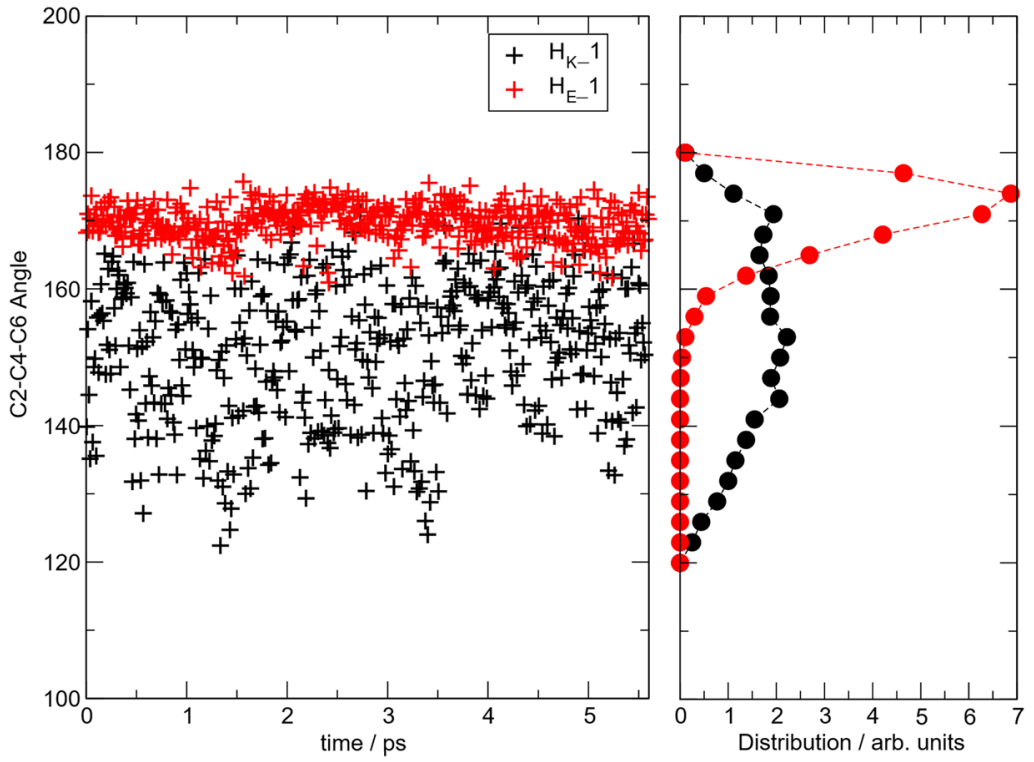

FIG. 5. Left: C2-C4-C6 angle as a function of simulation time. Right: 20 bins histogram distributions. dihedral angle of $173.5^{\circ}$ forces ring B slightly out of plane, as shown in the view on the right side in Fig. 4. Besides, a keto-enol species bearing a protonated methoxy group $\left(\mathbf{H}_{\mathrm{E} \_} \mathbf{8}\right)$ that interacts with the adjacent phenol oxygen $\left(\mathrm{r}_{\mathrm{O} 3 \mathrm{H}^{+}} \ldots \mathrm{O} 4 \mathrm{H}=1.984 \AA\right.$ ) and the keto-enol hydrogen bond $\left(\mathrm{r}_{\mathrm{O} 2 \mathrm{H}} \ldots \mathrm{O} 1 \mathrm{C}=1.615 \AA\right)$, is strongly unfavored, lying at $174.1 \mathrm{k} \mathrm{J} \mathrm{mol}^{-1}$.

Single point MP2 calculations have confirmed the two most stable species $\left(\mathbf{H}_{\mathbf{K} \_} \mathbf{l}\right.$ and $\left.\mathbf{H}_{\mathbf{E}_{-} \mathbf{1}}\right)$ of $[\mathrm{Cur}+\mathrm{H}]^{+}$, while the free energy ordering of higher energy species shows usually modest changes (Table IIIS).

Notably, in the gas phase, the most stable structure of protonated Cur is predicted to formally derive from protonation of the diketo form ( $\left.\mathbf{H}_{\mathbf{K}} \mathbf{1}\right)$, slightly favored over the ion obtained by protonation of the keto-enol tautomer $\left(\mathbf{H}_{\mathbf{E}} \mathbf{1}\right)$ by ca. $3.0 \mathrm{~kJ} \mathrm{~mol}^{-1}$, at variance with neutral Cur where the keto-enol configuration is more stable than the diketo form by ca. $20 \mathrm{~kJ} \mathrm{~mol}^{-1}$.

\section{Molecular dynamics}

From the structural point of view, protonated curcumin is a fairly rigid molecule. Apart from the obvious vibrational modes and $\mathrm{CH}_{3}$ rotations, we have found that the dynamics of the entire structure is dominated by a set of low energy modes which consists in a variation of the two angles reported in Fig. 4. In the diketo form, the angle formed by the $\mathrm{C} 2-\mathrm{C} 4-\mathrm{C} 6$ atoms varies between $130^{\circ}$ and $170^{\circ}$, thus indicating that the entire structure is "flipping" through the planar configuration. The keto-enol structure is more rigid with the same angle staying fairly localized around $170^{\circ}$ so confirming the findings shown by the minima in Fig. 4. The C2-C4-C6 angle as a function of simulation time is reported in Fig. 5, as computed for the $\mathbf{H}_{\mathbf{K} \_} \mathbf{l}$ and $\mathbf{H}_{\mathrm{E} \_} \mathbf{1}$ structures. The deviation from planarity is marked for the ketonic form and is due to the mentioned "butterfly" motion around the diketonic center. The enol configuration is instead characterized by a more rigid structure due to the conjugation that extends along the entire carbon structure.

Another source of additional flexibility in the ketonic form is due to the motion of the proton shared by the two carbonyl terminals. This motion is peculiar to the ketonic form and does not take place in the enolic one where the two protons attached to the two carbonyl terminals have been found to keep their positions along the entire dynamics. The situation is illustrated in Fig. 6 where we report a "top" and a "side" view of the protonated curcumin molecule in both ketonic ( $\mathbf{H}_{\mathbf{K} \_} \mathbf{1}$, top panels) and enolic ( $\mathbf{H}_{\mathbf{E} \_} \mathbf{1}$, bottom panels) forms. In order to grasp the dynamic motion of the protons, we have computed their density as an average over the entire trajectory. The
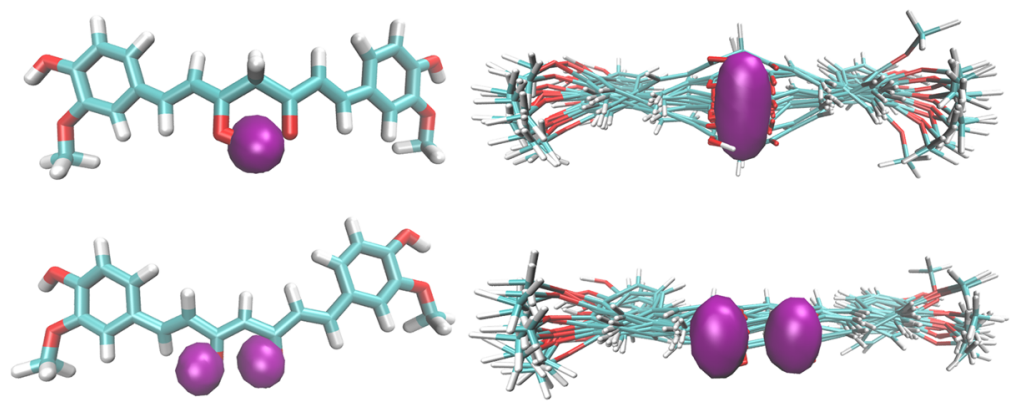

FIG. 6. Left: "Top" view of a reference structure for the keto (top) and enol (bottom) forms superimposed to the average proton density obtained from the entire $5 \mathrm{ps}$ trajectory. Right: "Side" view as before, but the conformational mobility of the curcumin skeleton is now illustrated by plotting a superposition of several structures during the entire trajectory (one every $400 \mathrm{fs}$ ). 
result is presented in Fig. 6 where the average position of the protons is rendered as a purple isosurface. As shown, the proton in the ketonic form is almost perfectly shared between the two symmetric $\mathrm{C}=\mathrm{O}$ terminals, while the two protons of the enolic form remain fairly localized without any sign of exchange. In the right panels of Fig. 6, we have also tried to render the peculiar motions of the chemical skeleton of curcumin by superimposing various snapshots of the trajectory. Again, we clearly see how flexible the ketonic form is when compared to the enolic one.

The behavior of the protons is also illustrated in terms of radial distribution functions in Fig. S12. In the ketonic form, the $(\mathrm{C}=\mathrm{O})-$ $\mathrm{H}^{+}$distance shows a large amplitude motion and is seen to vary between 1 and $2 \AA$ with two maxima, one at $1.1 \AA$ and another at $1.5 \AA$. These two maxima identify the most stable positions of the proton with respect to each oxygen: the short range one is due to the proton being directly attached to the oxygen and the long range one corresponds to the situation where the proton has migrated onto the other oxygen. In Fig. S12, we also report the radial distribution function for the $(\mathrm{C}=\mathrm{O})-\mathrm{H}^{+}$distance in the enolic form: only one peak can be seen that corresponds to both protons being attached to each oxygen.

\section{Spectral assignment}

The IRMPD spectrum of gaseous $[\mathrm{Cu}(\mathrm{Cur}-\mathrm{H})]^{+}$covering both the IR fingerprint and $\mathrm{NH} / \mathrm{OH}$ stretching ranges is compared in Fig. 7 with the calculated IR spectra of $\mathbf{C u} \mathbf{u}_{-} \mathbf{1}$ and $\mathbf{C u} \_\mathbf{1 1}$, the most stable species among those obtained from chelation of copper at either chain or ring binding sites of deprotonated Cur. In addition, a comprehensive presentation of the IR spectra of other identified structures is provided in Figs. S13 and S14.

The main experimental bands can be adequately explained by the calculated IR modes of the lowest energy structure, Cu_1, although the $\mathbf{C u} \mathbf{2}-\mathbf{C u} \mathbf{z}$ 7 members of the chain family of

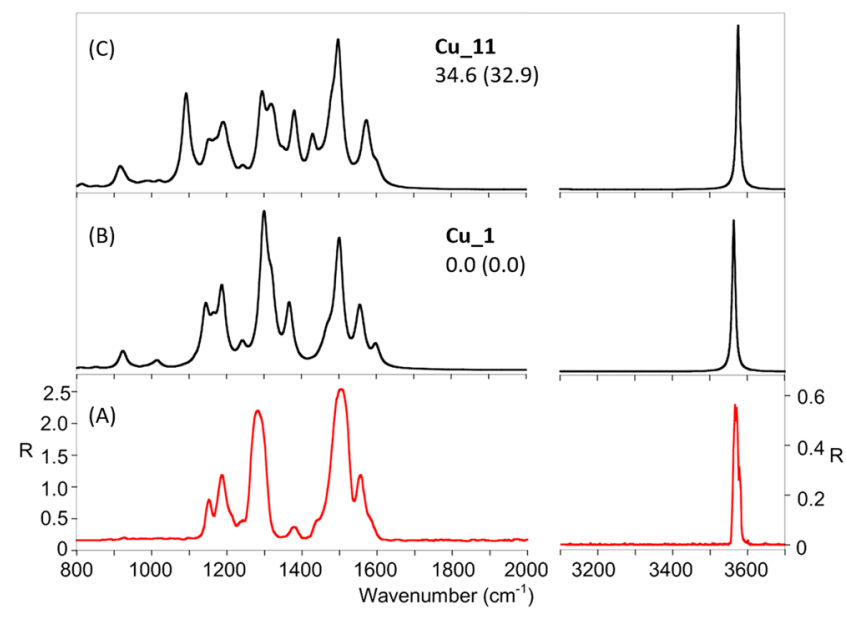

FIG. 7. The IRMPD spectrum of $[\mathrm{Cu}(\mathrm{Cur}-\mathrm{H})]^{+}$(a) compared with the linear IR spectra of optimized structures Cu_1 (b) and Cu_11 (c) calculated at the B3LYP/6$311+G(d, p)$ level of theory. Relative free energies and enthalpies (in brackets) calculated at the same level of theory at $298 \mathrm{~K}$ are reported in $\mathrm{kJ} \mathrm{mol}^{-1}$. The scale of the $y$-axis is the same for all theoretical IR spectra.
Cu-binding found within $15 \mathrm{~kJ} \mathrm{~mol}^{-1}$ present very similar IR features, with only some minor differences. As a result, their combined contributions as kinetically trapped conformers cannot be excluded in the gas-phase. ${ }^{80}$

The positions and intensities of the main IRMPD absorptions of $[\mathrm{Cu}(\mathrm{Cur}-\mathrm{H})]^{+}$along with the computed IR bands of the global minimum $\mathbf{C u} \_\mathbf{1}$ are listed in Table I together with a brief mode description.

Most bands in the fingerprint range result from extensive mode mixing and calculated spectra of $\mathbf{C u} \mathbf{u}_{-} \mathbf{1}$ predict fairly well the positions and (partially) the intensities of $[\mathrm{Cu}(\mathrm{Cur}-\mathrm{H})]^{+}$absorptions in both the explored ranges.

Among the most intense bands in the fingerprint range, the partially resolved features at 1150 and $1190 \mathrm{~cm}^{-1}$ encompass in plane $\mathrm{CH}$ and phenol $\mathrm{OH}$ bending vibrations together with methyl wagging and a ring deformation mode; the envelope of peaks centered at $1285 \mathrm{~cm}^{-1}$ comprises phenol C-OH stretching, $\mathrm{CH}$ and phenol $\mathrm{O} 4 \mathrm{H}$ bending, and ring deformation, besides chain and ring $\mathrm{CC}$ stretching modes. At higher frequencies, the prominent and quite broad band $\left(\mathrm{FWHM}=80 \mathrm{~cm}^{-1}\right.$ ) recorded at $1505 \mathrm{~cm}^{-1}$ embraces methyl scissoring, bending of the $\mathrm{CH}$ junction, and two strongly active modes with a predominantly mixed character of symmetric enol CC and C-O stretches, $\mathrm{CH}$ bending, and ring deformation. On the blue side, the poorly resolved absorption observed at $1557 \mathrm{~cm}^{-1}$ can be attributed to chain and ring $\mathrm{C}-\mathrm{C}$ stretches coupled with phenolic $\mathrm{OH}$ bending. Also, the weak shoulders at 1230, 1437, and $1590 \mathrm{~cm}^{-1}$ are in good agreement with the computed IR vibrations for $\mathrm{C}-\mathrm{OCH}_{3}$ stretch, $\mathrm{CH}$ bending, $\mathrm{CH}_{3}$ umbrella and scissoring modes, and chain CC stretch, respectively, while the small band at $1380 \mathrm{~cm}^{-1}$ is due to bending of $\mathrm{OH}$ and $\mathrm{C} 4 \mathrm{H}$ groups mixed with $\mathrm{CC}$ stretches of the chelating group.

In the high frequency part of the IRMPD spectrum, the strong absorbance at $3569 \mathrm{~cm}^{-1}$ is actually composed of two merged peaks well matched by the phenolic $\mathrm{OH}$ stretches, thus excluding the involvement of ring $\mathrm{OH}$ in copper chelation. The deletion of the hydrogen bond between the phenolic and the methoxyl groups in $\mathbf{C u} \_\mathbf{8}$ results in a blueshift of the phenolic $\mathrm{OH}$ stretch by ca. $70 \mathrm{~cm}^{-1}$, as previously observed in protonated tyrosine, ${ }^{37,81}$ in contrast with the experimental evidence. In addition, one can exclude any appreciable contribution of the phenate $\mathbf{C u} \mathbf{1} \mathbf{1 1}$ isomer based on the absence in the IRMPD spectrum of the highly active $\mathrm{C} 4 \mathrm{H}$ bending, phenol and enol $\mathrm{C}-\mathrm{OH}$ stretching modes expected at 1093, 1319 , and $1430 \mathrm{~cm}^{-1}$, respectively.

For the higher energy $\mathbf{C u} \mathbf{1 3}$ tautomer, signatures of the diketo form are the peaks predicted at $1098 \mathrm{~cm}^{-1}$, attached to the rocking of the methylene group coupled with the $\mathrm{C} 3 \mathrm{C} 4 \mathrm{C} 5$ stretching, and at 1658 and $1696 \mathrm{~cm}^{-1}$, associated with the $\mathrm{C}=\mathrm{O}$ vibrations, which are by no means observed in the experimental spectrum.

Overall, the most stable complex $\mathbf{C u} \_\mathbf{1}$ with the likely contribution of low-lying rotamers $\mathbf{C u} \_\mathbf{2}$ and $\mathbf{C u} \mathbf{u}$, or kinetically trapped Cu_4 -Cu_7 rotamers where copper ion is bound to the $\mathrm{O}$-atoms of curcumin deprotonated at the mid diketo functionality, well interprets the main IRMPD features of the bare $[\mathrm{Cu}(\mathrm{Cur}-\mathrm{H})]^{+}$ion. Interestingly, these results confirm the metal coordination by the keto-enol moiety ${ }^{4,15,20}$ and are consistent with previous evidence in condensed phase (in solid state and in different solvents) on mononuclear $\mathrm{Cu}(\mathrm{II})$-curcumin complexes bearing acetate and water ligands where the involvement of phenolic $\mathrm{OH}$ group in metal 
TABLE I. Observed IRMPD resonances of the $[\mathrm{Cu}(\mathrm{Cur}-\mathrm{H})]^{+}$complex and calculated vibrational frequencies of the $\mathrm{Cu} \_1$ isomer.

\begin{tabular}{|c|c|c|}
\hline IRMPD $^{\mathrm{a}}$ & Calculated $\mathrm{IR}^{\mathrm{a}, \mathrm{b}, \mathrm{c}}$ & Vibrational mode \\
\hline \multicolumn{3}{|c|}{ Cu_1 } \\
\hline 925 & $924(714)$ & $\operatorname{ring}_{A, B}$ def \\
\hline \multirow[t]{2}{*}{1150} & $1145(795)$ & $\mathrm{C} 4 \mathrm{H} \beta, \mathrm{CH}_{3} \beta_{\mathrm{r}}$ \\
\hline & $1165(1041)$ & $\mathrm{OH} \beta, \mathrm{CH}_{3} \beta_{\mathrm{w}}, \mathrm{C}^{\prime} \mathrm{H} \beta, \mathrm{C}^{\prime \prime} \mathrm{H} \beta$ \\
\hline \multirow[t]{2}{*}{1190} & $1187(2374)$ & $\mathrm{OH} \beta, \mathrm{CH}_{3} \beta_{\mathrm{w}}, \mathrm{C} 2^{\prime} \mathrm{H} \beta, \mathrm{C} 2^{\prime \prime} \mathrm{H} \beta$ \\
\hline & $1192(518)$ & $\mathrm{CH}_{3} \beta_{\mathrm{w}}, \mathrm{CH} \beta$ \\
\hline 1230 (shoulder) & $1242(659)$ & $\mathrm{C}-\mathrm{OCH}_{3} \sigma$, chain $\mathrm{CH} \beta$ \\
\hline \multirow{3}{*}{1285} & $1295(890)$ & $\mathrm{C} 1 \mathrm{H} \beta, \mathrm{C} 7 \mathrm{H} \beta, \mathrm{C}^{\prime} \mathrm{H} \beta, \mathrm{C} 6^{\prime \prime} \mathrm{H} \beta$ \\
\hline & $1301(4368)$ & $\operatorname{ring}_{\mathrm{A}, \mathrm{B}}$ def, $\mathrm{Cl}^{\prime} \mathrm{C} 1 \sigma, \mathrm{C}^{-} 1^{\prime \prime} \sigma, \mathrm{CH} \beta$ \\
\hline & $1321(2285)$ & $\mathrm{C}-\mathrm{O} 4 \mathrm{H} \sigma, \mathrm{C}-\mathrm{O} 6 \mathrm{H} \sigma, \mathrm{C} 1 \mathrm{H} \beta, \mathrm{C} 7 \mathrm{H} \beta$ \\
\hline 1380 & $1368(2256)$ & $\mathrm{C} 4 \mathrm{H} \beta, \mathrm{C}-\mathrm{OH} \beta, \mathrm{C} 3-\mathrm{C} 4-\mathrm{C} 5 \sigma$ \\
\hline 1437 (shoulder) & $1453(169)$ & $\mathrm{CH}_{3}$ umbrella \\
\hline \multirow[t]{4}{*}{1505} & $1468(505)$ & $\mathrm{C}^{\prime \prime} \mathrm{H}_{3} \beta_{\mathrm{s}}$ \\
\hline & $1476(384)$ & $\mathrm{C} 4-\mathrm{H} \beta$ \\
\hline & $1493(851)$ & $\mathrm{CO} 1 \sigma, \mathrm{CO} 2 \sigma, \mathrm{C} 1 \mathrm{H} \beta, \mathrm{C} 7 \mathrm{H} \beta$ \\
\hline & $1502(4353)$ & $\mathrm{CH} \beta, \operatorname{ring}_{\mathrm{A}, \mathrm{B}} \operatorname{def}$ \\
\hline \multirow[t]{2}{*}{1557} & $1554(1322)$ & $\mathrm{CC} \sigma, \mathrm{COH} \beta$ \\
\hline & $1561(889)$ & $\mathrm{C} 1 \mathrm{C} 2 \sigma, \mathrm{C} 6 \mathrm{C} 7 \sigma, \mathrm{C} 1 \mathrm{H} \beta, \mathrm{C} 2 \mathrm{H} \beta, \mathrm{C} 6 \mathrm{H} \beta, \mathrm{C} 7 \mathrm{H} \beta$ \\
\hline 1590 (shoulder) & $1599(583)$ & $\mathrm{C} 1 \mathrm{C} 2 \sigma, \mathrm{C} 6 \mathrm{C} 7 \sigma, \operatorname{ring}_{\mathrm{A}-\mathrm{B}} \operatorname{def}$ \\
\hline \multirow[t]{2}{*}{$3569^{\mathrm{d}}$} & $3642(2395)$ & $\mathrm{OH} \sigma$ asymm \\
\hline & $3643(161)$ & $\mathrm{OH} \sigma$ symm \\
\hline
\end{tabular}

a $\mathrm{In} \mathrm{cm}^{-1}$

$\mathrm{b}$ The calculated intensities (in parentheses) are in $\mathrm{km} \mathrm{mol}^{-1}$. Bands with an intensity lower than $50 \mathrm{~km} \mathrm{~mol}^{-1}$ are not included.

${ }^{c}$ All calculated IR frequencies in the $800-2000 \mathrm{~cm}^{-1}\left(3100-3700 \mathrm{~cm}^{-1}\right)$ range are scaled by a factor of $0.978(0.958)$.

${ }^{\mathrm{d}} \sigma=$ stretch; $\beta$ = bend; $\beta_{\mathrm{s}}=$ scissoring; $\beta_{\mathrm{w}}=$ wagging; $\beta_{\mathrm{r}}=$ rocking, def = deformation.

complexation is excluded, ${ }^{61}$ thus preserving the antioxidant property of Cur.

The IRMPD spectrum of the $[\mathrm{Cur}+\mathrm{H}]^{+}$ion is presented together with the calculated IR spectra of the lowest-lying diketo $\left(\mathbf{H}_{\mathbf{K}_{-}} \mathbf{1}\right)$ and keto-enol $\left(\mathbf{H}_{\left.\mathrm{E}_{-} \mathbf{1}\right)}\right.$ species for comparison purposes (Fig. 8). The linear IR spectra of the other assayed structures are provided in Figs. S15, S16, and S17. Because other structures including $\mathbf{H}_{\mathbf{K} \_2}-\mathbf{H}_{\mathbf{K} \_5}$ and $\mathbf{H}_{\mathbf{E} \_} \mathbf{2}-\mathbf{H}_{\mathbf{E} \_} \mathbf{5}$ are found within 8.5 and $9.6 \mathrm{~kJ}$ $\mathrm{mol}^{-1}$, respectively, and present very similar IR spectra matching the experimental IRMPD spectrum, their contribution cannot be discarded.

It is clear that the experimental spectrum does not conform

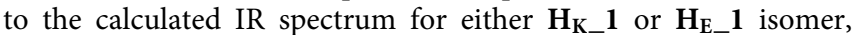
whose features appear rather complementary in the $1200-1600 \mathrm{~cm}^{-1}$ range. Indeed, the combined contribution by these structures to the gaseous sampled ions is compatible with their close free energy values (within $3.0 \mathrm{~kJ} \mathrm{~mol}^{-1}$ ). Moreover, given the significant keto-enol isomerization barrier, ${ }^{82}$ the sampled population of electrosprayed ions might well reflect the ion distribution formed by protonation in solution where neutral Cur exists only in the keto-enol configuration, while a measurable amount of the diketo form has been revealed merely in nonpolar $\mathrm{CCl}_{4}{ }^{76}$ Keto-enol Cur protonation at the carbonyl oxygen yields $\mathbf{H}_{\mathrm{E} \_} \mathbf{l}$ while protonation at the enol $\mathrm{CH}$ leads to $\mathbf{H}_{\mathbf{K}} \_\mathbf{1}$. However, the latter process is rather kinetically disfavored due to the high barriers known to be involved in proton transfers at carbon. ${ }^{83,}$

Indeed, several cases where the relative amount of isomers extracted from solution by ESI does not adhere to the corresponding gas phase stabilities have been already discussed.

The thermally averaged spectra weighted according to the relative $\Delta G$ values of each species presented in Fig. S18 support a joint presence of $\mathbf{H}_{K_{-}} \mathbf{l}$ and $\mathbf{H}_{\mathrm{E}_{-} \mathbf{1}}$. However, the best agreement is found when the contribution of $\mathbf{H}_{\mathbf{K}_{-}} \mathbf{1}$ and $\mathbf{H}_{\mathbf{E}_{-} \mathbf{1}}$ species in 1:3 ratio is considered to build up the averaged spectrum of Fig. 8(b).

Herein, features belonging to $\mathbf{H}_{\mathbf{K}_{-} \mathbf{1}}$ and $\mathbf{H}_{\mathbf{E}_{-}} \mathbf{1}$, as a representative of low lying protonated diketo and keto-enol forms, respectively, and the ones endowed with the best matching profiles are described in Table VS. In the fingerprint range, the intense band centered at $1147 \mathrm{~cm}^{-1}$ mainly arises from $\mathrm{OH}$ bending, $\mathrm{CC}$ stretching, and chain $\mathrm{CH}$ bending, predicted at 1138 and $1150 \mathrm{~cm}^{-1}\left(\mathbf{H}_{\mathrm{E} \_} \mathbf{1}\right)$ and from $\mathrm{CH}_{2}$ wagging and either protonated carbonyl $\mathrm{OH}$ or phenol $\mathrm{OH}$ bendings, calculated at 1106, 1108, 1118, and $1160 \mathrm{~cm}^{-1}\left(\mathbf{H}_{\mathbf{K}} \mathbf{1}\right)$.

The absorption at $1294 \mathrm{~cm}^{-1}$ is in good agreement with the main contributions of the $\mathrm{O} 1 \mathrm{H}$ bending, chain $\mathrm{CC}, \mathrm{CO} 2$, and $\mathrm{CO} 6$ stretching modes, and ring deformation, calculated at 1282 and $1305 \mathrm{~cm}^{-1}$ for $\mathbf{H}_{\mathbf{E} \_} \mathbf{l}$ and at $1269 \mathrm{~cm}^{-1}$ for $\mathbf{H}_{\mathbf{K} \_} \mathbf{1}$ together with the phenol $\mathrm{OH}$ bending coupled with the bending modes of the alkenyl chain $\mathrm{CH}$ at $1309 \mathrm{~cm}^{-1}$ and ring deformation, $\mathrm{O} 1 \mathrm{H}$ bending 


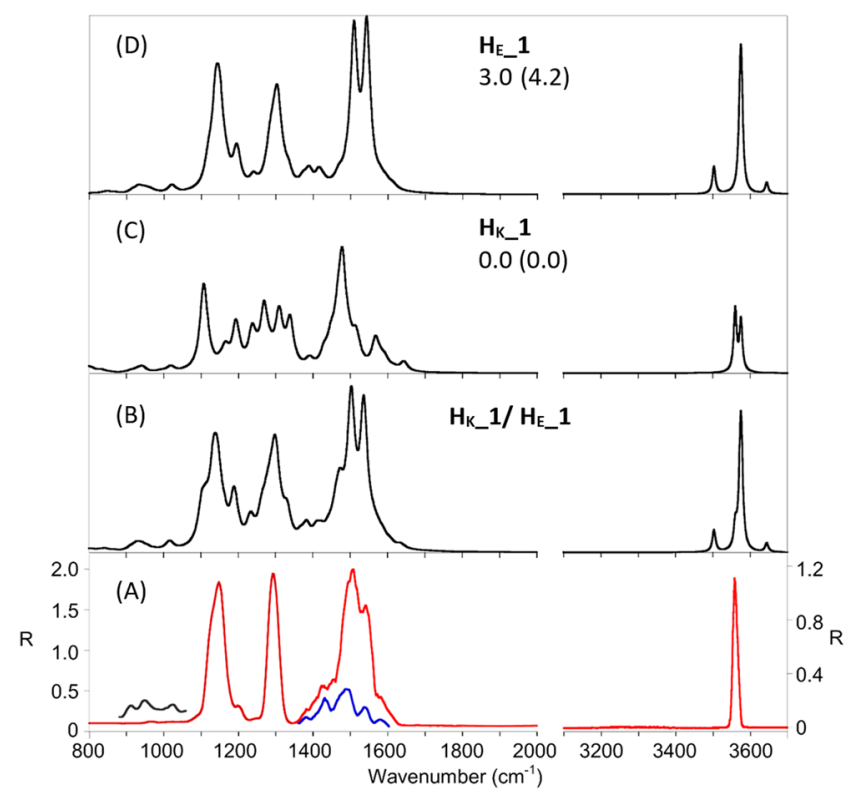

FIG. 8. The IRMPD spectrum of $\left[\mathrm{Cur}+\mathrm{H}^{+}\right.$(a) compared with the linear IR spectra of optimized structures $\mathrm{H}_{\mathrm{K}-1} 1$ (c) and $\mathrm{H}_{\mathrm{E}_{-}} 1$ (d) calculated at the B3LYP/6$311+G(d, p)$ level of theory. Panel $(b)$ reports a theoretical spectrum averaged from $H_{K_{-}} 1$ and $H_{E_{-}} 1$ in 1:3 ratio, respectively, showing the plausible contribution of the two isomers to the sampled gas-phase population. Relative free energies and enthalpies (in brackets) calculated at the same level of theory at $298 \mathrm{~K}$ are reported in $\mathrm{kJ} \mathrm{mol}^{-1}$. The scale of the $\mathrm{y}$-axis is the same for all theoretical IR spectra.

and CO1 stretch expected at $1339 \mathrm{~cm}^{-1}\left(\mathbf{H}_{\mathbf{K}} \mathbf{1}\right)$. Also, the envelope of poorly resolved peaks between 1380 and $1600 \mathrm{~cm}^{-1}$ agrees with an admixture of contributing protonated diketo and ketoenol tautomers. The first peak centered at $1382 \mathrm{~cm}^{-1}$ encompasses the $\mathrm{CO} 2$ stretching and $\mathrm{C} 4 \mathrm{H}$, phenol $\mathrm{OH}$, and $\mathrm{CH}$ chain bending modes, predicted at 1373 and $1389 \mathrm{~cm}^{-1}\left(\mathbf{H}_{\mathbf{E}_{-}} \mathbf{1}\right)$; the second band at $1433 \mathrm{~cm}^{-1}$ comprises $\mathrm{CO} 1$ stretch coupled with $\mathrm{CH}_{3}$ umbrella and deformation of ring $\mathrm{A}$, calculated at $1414 \mathrm{~cm}^{-1}\left(\mathbf{H}_{\left.\mathrm{E}_{-} \mathbf{1}\right)}\right)$ and ring A deformation, and $\mathrm{CH}_{2}$ wagging and $\mathrm{C} \mathrm{H}_{3}$ umbrella, predicted at 1429 and $1448 \mathrm{~cm}^{-1}\left(\mathbf{H}_{\mathbf{K}} \mathbf{1}\right)$, respectively. Also, the third band at $1487 \mathrm{~cm}^{-1}$ is due to contributions by $\mathbf{H}_{\mathbf{K}} \mathbf{1}$, with $\mathrm{C}_{9} \mathrm{H}_{3}$ umbrella at $1466 \mathrm{~cm}^{-1} ; \mathrm{CH}_{2}$ wagging, $\mathrm{C} 2 \mathrm{C} 3$, and $\mathrm{CH}_{3}$ scissoring at $1479 \mathrm{~cm}^{-1}$; CO1 stretch coupled with $\mathrm{O} 1 \mathrm{H}$ bending at $1494 \mathrm{~cm}^{-1}$; ring $\mathrm{B}$ breathing at $1514 \mathrm{~cm}^{-1}$, and by $\left(\mathbf{H}_{\mathrm{E}_{-}} \mathbf{1}\right)$, with $\mathrm{CH}_{3}$ scissoring at $1470 \mathrm{~cm}^{-1}$; O1H bending and $\mathrm{C} 3 \mathrm{C} 4 \mathrm{C} 5$ stretching at $1488 \mathrm{~cm}^{-1}$ and ring breathing, mixed with $\mathrm{CH}$ bending at $1509 \mathrm{~cm}^{-1}$. The last bands at 1540 and $1582 \mathrm{~cm}^{-1}$ are mainly due to ring deformation, $\mathrm{CH}, \mathrm{O} 1 \mathrm{H}$, and $\mathrm{O} 2 \mathrm{H}$ bendings predicted at $1543 \mathrm{~cm}^{-1}$, and ring $\mathrm{OH}$ bending at $1580 \mathrm{~cm}^{-1}\left(\mathbf{H}_{\mathrm{E} \_} \mathbf{1}\right)$, together with CC stretch of ring A at $1567 \mathrm{~cm}^{-1}$ and coupled $\mathrm{O} 1 \mathrm{H}$ bending with the $\mathrm{C} 6 \mathrm{C} 7$ stretching mode at $1594 \mathrm{~cm}^{-1}$ (H. $\left.\mathbf{H}_{\mathbf{K}} \mathbf{1}\right)$.

In the fingerprint range, a relevant presence of higher energy species, including protonated diketo $\left(\mathbf{H}_{\mathbf{K}} \_\right.$5-11) and keto-enol (HE_5-7) conformers, which do not ensure an improved agreement with the experimental spectrum, can be ruled out on energetic basis. Also, high energy phenate isomers $\left(\mathbf{H}_{\mathbf{E} \_} \mathbf{8}\right)$, showing intense bands at 1368,1445 , and $1630 \mathrm{~cm}^{-1}$ corresponding to the $\mathrm{C} 3 \mathrm{O} 1$ stretch, the $\mathrm{C}_{9} \mathrm{H}_{3}$ bending coupled with the $\mathrm{O} 1 \mathrm{H}$ one and the $\mathrm{O} 1 \mathrm{H}$ bending coupled with the CC stretches of the alkyl chain, are inconsistent with experimental evidence.

In the $\mathrm{OH}$ stretch spectral region, the prominent IRMPD feature at $3558 \mathrm{~cm}^{-1}$ is the one less satisfactorily matched with the phenol $\mathrm{OH}$ stretches of rings $\mathrm{A}$ and $\mathrm{B}$ calculated for $\mathbf{H}_{\mathbf{K}_{-} \mathbf{1}}$ as two partially resolved peaks at 3561 and $3577 \mathrm{~cm}^{-1}$. These modes are instead predicted as merged bands at 3578 and $3581 \mathrm{~cm}^{-1}$ for $\mathbf{H}_{\mathbf{E}} \mathbf{1}$, which, however, presents two additional small peaks in the explored range, i.e., the $\mathrm{H}$-bonded $\mathrm{O} 1 \mathrm{H}$ and the free $\mathrm{O} 2 \mathrm{H}$ stretches, expected at 3507 and $3648 \mathrm{~cm}^{-1}$, where $[\mathrm{Cur}+\mathrm{H}]^{+}$presents hardly any vibrational activity. In $\mathbf{H}_{\mathbf{K}} \mathbf{1}$, the $\mathrm{O} 1 \mathrm{H}$ stretch engaged in strong $\mathrm{H}$ bond is dramatically redshifted at $2317 \mathrm{~cm}^{-1}$, which is out of the explored range.

The simultaneous presence of the lowest energy protonated diketo and keto-enol tautomers in the sampled [Cur $+\mathrm{H}]^{+}$ion population is confirmed by comparing their averaged IR spectrum with the experimental one. It is noteworthy that the contribution in a 1:3 ratio of $\mathbf{H}_{\mathbf{K}} \mathbf{1}$ and $\mathbf{H}_{\mathbf{E} \_\mathbf{1}}$, exposed in Fig. 8(b), shows the closest correspondence in the fingerprint range and may also be compatible with the presence of a single prominent band in the $\mathrm{XH}$ stretching region. Indeed, according to previous evidence, the absence of the bands predicted at 3507 and $3648 \mathrm{~cm}^{-1}\left(\mathbf{H}_{\mathrm{E} \_} \mathbf{1}\right)$ may be ascribed to the significant redshift and broadening of the absorption frequencies that affect stretching modes involved in strong $\mathrm{H}$-bond ${ }^{33,89}$ and to an intensity too weak to exceed the threshold limit for detection, respectively.

As described in previous instances, ${ }^{90,91}$ a possible cause for the inadequacy of harmonic DFT calculations to describe this part of the IRMPD spectrum may be related to anharmonic effects that emerge when the proton is shared between comparably basic sites, such as the two equivalent carbonyl oxygens in the curcumin diketo tautomer. Indeed, MD calculations are apt to describe anharmonicity and temperature effects in vibrational spectra. However, a comprehensive MD evaluation on the assayed relatively large molecular systems is presently beyond the scope of the available computational resources.

\section{CONCLUSIONS}

The protective influence of curcumin against metal-induced oxidative damage, besides the improved stability and cytotoxic activity of curcumin copper complex, is a promising domain of exploration. Here, a detailed description of $[\mathrm{Cu}(\mathrm{Cur}-\mathrm{H})]^{+}$and $[\mathrm{Cur}+$ $\mathrm{H})]^{+}$ions as naked species has been addressed by a combination of IRMPD spectroscopy, CID experiments, and quantum chemical calculations as a biophysical tool to unveil curcumin's binding site, explore the influence of metalation/protonation on the geometric determinants of the electrosprayed species, and identify diagnostic features of these interactions.

The highly symmetrical structure of curcumin presents a central keto-enol/diketo functionality flanked by two peripheral aryl groups, each bearing hydroxyl and methoxyl substituents in ortho relationship. The gathered evidence reveals the central ketoenol/diketo functionality as the main actor both in carrying an added proton and in coordinating a biologically active metal such as $\mathrm{Cu}$ (II). While both central and peripheral $\mathrm{O}$-containing groups are suitable for establishing hydrogen bonds and chelation interactions, it 
is clearly the beta-diketo linker to be favored. Deprotonation at this site yields a highly delocalized anion which may present increased electron density at the ligating $\mathrm{O}$-atoms due to conjugative electron donation from the hydroxyl group in para position to the chain link. Thus, in the $\mathrm{Cu}$ (II) complex, the two $\mathrm{Cu}-\mathrm{O}$ symmetrical bonds of structure $\mathrm{Cu}$ _1 present significantly polar character associated with a net charge of 0.89 on the metal and of -0.79 on each ligated $\mathrm{O}$-atom. The bonding framework and peculiar electron density distribution is likely bound to the recognized biological roles of curcumin. Further studies are aimed to integrate this assay of the vibrational features of $\mathrm{Cu}$ (II)-curcumin complexes by sampling the stretching mode of the most interesting $\mathrm{Cu}-\mathrm{O}$ bond expected to be IRMPD active in the $400-500 \mathrm{~cm}^{-1}$ range.

A mixture of two close-lying isomers is found to contribute to the IRMPD spectrum of $[\mathrm{Cur}+\mathrm{H}]^{+}$, which may present the added proton attached to either a diketo $\left(\mathbf{H}_{\mathbf{K} \_} \mathbf{1}\right)$ or keto-enol tautomer $\left(\mathbf{H}_{\mathrm{E} \_} \mathbf{1}\right)$ and a bent or nearly planar geometry, respectively. Although $\mathbf{H}_{\mathbf{K}_{-}} \mathbf{l}$ is the predicted lowest energy structure, spectral evidence is consistent with a predominant contribution of $\mathbf{H}_{\mathrm{E} \_} \mathbf{1}$ in the ion population delivered in the gas phase by ESI, a likely reflection of the Cur tautomeric equilibrium in solution. It may be underlined that the present study has succeeded in unveiling the early $1: 1 \mathrm{Cu}$ (II) curcumin complex, previously unnoticed in solution. While the gas phase characterization obviously refers to an isolated species which has no direct counterpart in curcumin chemistry in biological media, still it is interesting to note that the assayed complex retains the free phenol active sites that are held responsible for radical scavenging activity.

\section{SUPPLEMENTARY MATERIAL}

See supplementary material for ESI FT-ICR mass spectrum of $\mathrm{CuSO}_{4} /$ curcumin solution (Fig. S1); photodissociation mass spectra (Figs. S2 and S5); CID assay and fragmentation pathway of [Cur $+\mathrm{H}]^{+}$(Figs. S3 and S4); optimized geometries of $[\mathrm{Cu}(\mathrm{Cur}-\mathrm{H})]^{+}$ (Figs. S6 and S7), [Cur $-\mathrm{H}]^{-}$(Fig. S8) and [Cur $\left.+\mathrm{H}\right]^{+}$(Figs. S9, $\mathrm{S} 10$, and S11); radial distribution functions for the $\mathrm{O}-\mathrm{H}(+)$ distances (Fig. S12); comparison between experimental IRMPD and computed IR spectra of $[\mathrm{Cu}(\mathrm{Cur}-\mathrm{H})]^{+}$(Figs. S13 and S14) and $[\mathrm{Cur}+\mathrm{H}]^{+}$(Figs. S15, S16, S17, and S18); thermodynamic data for $[\mathrm{Cu}(\mathrm{Cur}-\mathrm{H})]^{+}$(Table IS) and for $[\mathrm{Cur}+\mathrm{H}]^{+}$(Table IIIS); selected dihedral angles for $[\mathrm{Cu}(\mathrm{Cur}-\mathrm{H})]^{+}$(Table IIS) and for [Cur $+\mathrm{H}]^{+}$(Table IVS); and experimental IRMPD bands and calculated vibrational frequencies for [Cur $+\mathrm{H}]^{+}$(Table VS). Any additional computational detail and material (Cartesian coordinate xyz files, calculated vibrational frequencies for all structures, etc.) is available upon request.

\section{ACKNOWLEDGMENTS}

We are grateful to Jean-Michel Ortega and the CLIO team. We also thank Annito Di Marzio for experiments at the OPO/OPA laser coupled to mass spectrometry instrumentation in Roma. This work has been funded by the Università degli Studi di Roma La Sapienza. This research has been supported by the project CALIPSOplus under the Grant Agreement No. 730872 from the EU Framework Programme for Research and Innovation HORIZON 2020. Financial Support from the National FT-ICR network (No. FR3624 CNRS) for conducting the research is gratefully acknowledged.

\section{REFERENCES}

${ }^{1}$ S. Banerjee and A. R. Chakravarty, Acc. Chem. Res. 48, 2075 (2015).

${ }^{2}$ E. Ferrari, R. Benassi, S. Sacchi, F. Pignedoli, M. Asti, and M. Saladini, J. Inorg. Biochem. 139, 38 (2014).

${ }^{3}$ J. Bernal, J. A. Mendiola, E. Ibanez, and A. Cifuentes, J. Pharm. Biomed. Anal. 55, 758 (2011).

${ }^{4}$ S. Wanninger, V. Lorenz, A. Subhanb, and F. T. Edelmann, Chem. Soc. Rev. 44, 4986 (2015).

${ }^{\mathbf{5}}$ M. M. Yallapu, M. Jaggi, and S. C. Chauhan, Drug Discovery Today 17, 71 (2012).

${ }^{6}$ D. Yanagisawa, N. Shirai, T. Amatsubo, H. Taguchi, K. Hirao, M. Urushitani, S. Morikawa, T. Inubushi, M. Kato, F. Kato, K. Morino, H. Kimura, I. Nakano, C. Yoshida, T. Okada, M. Sano, Y. Wada, K. N. Wada, A. Yamamoto, and I. Tooyama, Biomaterials 31, 4179 (2010).

${ }^{7}$ A. Barik, B. Mishra, L. Shen, H. Mohan, R. M. Kadam, S. Dutta, H. Y. Zhang, and K. I. Priyadarsini, Free Radicals Biol. Med. 39, 811 (2005).

${ }^{8}$ A. Barik, B. Mishra, A. Kunwar, R. M. Kadam, L. Shen, S. Dutta, S. Padhye, A. K. Satpati, H. Y. Zhang, and K. I. Priyadarsini, Eur. J. Med. Chem. 42, 431 (2007).

${ }^{9}$ H. H. Tønnesen, M. Másson, and T. Loftsson, Int. J. Pharm. 244, 127 (2002).

${ }^{10}$ Y. Li, Q. Zou, C. Yuan, S. Li, R. Xing, and X. Yan, Angew. Chem., Int. Ed. 57, 17084 (2018).

${ }^{11}$ G. Shoba, D. Joy, T. Joseph, M. Majeed, R. Rajendran, and P. S. Srinivas, Planta Med. 64, 353 (1998).

${ }^{12}$ L. Li, F. S. Braiteh, and R. Kurzrock, Cancer 104, 1322 (2005).

${ }^{13}$ A. Safavy, K. P. Raisch, S. Mantena, L. L. Sanford, S. W. Sham, N. Rama Krishna, and J. A. Bonner, J. Med. Chem. 50, 6284 (2007).

${ }^{14}$ E. Ferrari, F. Pignedoli, C. Imbriano, G. Marverti, V. Basile, E. Venturi, and M. Saladini, J. Med. Chem. 54, 8066 (2011).

${ }^{15}$ E. Ferrari, M. Asti, R. Benassi, F. Pignedoli, and M. Saladini, Dalton Trans. 42, 5304 (2013).

${ }^{16}$ Z. Kovacevic, S. D. Kalinowski, B. D. Lovejoy, Y. Yu, S. Y. Rahmanto, C. P. Sharpe, V. P. Bernhardt, and R. Richardson, Curr. Top. Med. Chem. 11, 483 (2011).

${ }^{17}$ R. Pettinari, F. Marchetti, C. Di Nicola, and C. Pettinari, Eur. J. Inorg. Chem. 2018, 3521 .

${ }^{18}$ R. Pettinari, F. Marchetti, F. Condello, C. Pettinari, G. Lupidi, R. Scopelliti, and S. Mukhopadhyay, T. Riedel, and P. J. Dyson, Organometallics 33, 3709 (2014).

${ }^{19}$ M. Sagnou, D. Benaki, C. Triantis, T. Tsotakos, V. Psycharis, C. P. Raptopoulou, I. Pirmettis, M. Papadopoulos, and M. Pelecanou, Inorg. Chem. 50, 1295 (2011).

${ }^{20}$ M. Asti, E. Ferrari, S. Croci, G. Atti, S. Rubagotti, M. Iori, P. C. Capponi, A. Zerbini, M. Saladini, and A. Versari, Inorg. Chem. 53, 4922 (2014).

${ }^{21}$ B. Banik, K. Somyajit, G. Nagaraju, and A. R. Chakravarty, Dalton Trans. 43, 13358 (2014).

${ }^{22}$ T. D. Fridgen, Mass Spectrom. Rev. 28, 586 (2009).

${ }^{23}$ N. C. Polfer and J. Oomens, Mass Spectrom. Rev. 28, 468 (2009).

${ }^{24}$ L. Jasikovà and J. Roithovà, Chem.-Eur. J. 24, 3374 (2018).

${ }^{25}$ J. Oomens, B. G. Sartakov, G. Meijer, and G. von Helden, Int. J. Mass Spectrom. 254, 1 (2006).

${ }^{26}$ B. Chiavarino, P. Maitre, S. Fornarini, and M. E. Crestoni, J. Am. Soc. Mass Spectrom. 24, 1603 (2013).

${ }^{27}$ B. Chiavarino, M. E. Crestoni, M. Schütz, A. Bouchet, S. Piccirillo, V. Steinmetz, O. Dopfer, and S. Fornarini, J.Phys. Chem. A 118, 7130 (2014).

${ }^{28}$ N. Heine, T. I. Yacovitch, F. Schubert, C. Brieger, D. M. Neumark, and K. R. Asmis, J. Phys. Chem. A 118, 7613 (2014).

${ }^{29}$ R. K. Sinha, D. Scuderi, P. Maitre, B. Chiavarino, M. E. Crestoni, and S. Fornarini, J. Phys. Chem. Lett. 6, 1605 (2015).

${ }^{30}$ M. T. Rodgers, P. B. Armentrout, J. Oomens, and J. D. Steill, J. Phys. Chem. A 112, 2258 (2008).

${ }^{31}$ J. K. Martens, I. Compagnon, E. Nicol, T. B. McMahon, C. Clavaguera, and G. Ohanessian, J. Phys. Chem. Lett. 3, 3320 (2012). 
${ }^{32}$ M. E. Crestoni, B. Chiavarino, D. Scuderi, A. Di Marzio, and S. Fornarini, J. Phys. Chem. B 116, 8771 (2012).

${ }^{33}$ B. Gregori, L. Guidoni, B. Chiavarino, D. Scuderi, E. Nicol, G. Frison, S. Fornarini, and M. E. Crestoni, J. Phys. Chem. B 118, 12371 (2014).

${ }^{34}$ R. Coates, C. P. McNary, G. C. Boles, G. Berden, J. Oomens, and P. B. Armentrout, Phys. Chem. Chem. Phys. 17, 25799 (2015).

${ }^{35}$ A. L. Patrick, C. N. Stedwell, and N. C. Polfer, Anal. Chem. 86, 5547 (2014).

${ }^{36}$ D. Corinti, A. De Petris, C. Coletti, N. Re, B. Chiavarino, S. Fornarini, and M. E. Crestoni, ChemPhysChem 18, 318 (2017).

${ }^{37}$ D. Corinti, B. Gregori, L. Guidoni, D. Scuderi, T. B. McMahon, B. Chiavarino, S. Fornarini, and M. E. Crestoni, Phys. Chem. Chem. Phys. 20, 4429 (2018).

${ }^{38}$ J.-Y. Salpin, S. Guillaumont, J. Tortajada, L. MacAleese, J. Lemaire, and P. Maitre, ChemPhysChem 8, 2235 (2007).

${ }^{39}$ Y.-W. Nei, K. T. Crampton, G. Berden, J. Oomens, and M. T. Rodgers, J. Phys. Chem. A 117, 10634 (2013).

${ }^{40}$ F. Lanucara, M. E. Crestoni, B. Chiavarino, S. Fornarini, O. Hernandez, D. Scuderi, and P. Maitre, RSC Adv. 3, 12711 (2013).

${ }^{41}$ M. R. Ligare, A. M. Rijs, G. Berden, M. Kabelac, D. Nachtigallova, J. Oomens, and M. S. De Vries, J. Phys. Chem. B 119, 7894 (2015).

${ }^{42}$ B. Chiavarino, M. E. Crestoni, S. Fornarini, D. Scuderi, and J.-Y. Salpin, Inorg. Chem. 54, 3513 (2015).

${ }^{43}$ R. R. Wu, B. Yang, C. E. Frieler, G. Berden, J. Oomens, and M. T. Rodgers, Phys. Chem. Chem. Phys. 17, 25978 (2015).

${ }^{44}$ N. C. Polfer, J. J. Valle, D. T. Moore, J. Oomens, J. R. Eyler, and B. Bendiak, Anal. Chem. 78, 670 (2006).

${ }^{45}$ B. Schindler, L. Barnes, G. Renois, C. Gray, S. Chambert, S. Fort, S. Flitsch, C. Loison, A.-R. Allouche, and I. Compagnon, Nat. Commun. 8, 973 (2017).

${ }^{46}$ H. Elferink, M. E. Severijnen, J. Martens, R. A. Mensik, G. Berden, J. Oomens, F. P. J. T. Rutjes, A. M. Rijs, and T. J. Boltje, J. Am. Chem. Soc. 140, 6034 (2018).

${ }^{47}$ J. Martens, V. Koppen, G. Berden, F. Cuyckens, and J. Oomens, Anal. Chem. 89, 4359 (2017).

${ }^{48}$ A. De Petris, A. Ciavardini, C. Coletti, N. Re, B. Chiavarino, M. E. Crestoni, and S. Fornarini, J. Phys. Chem. Lett. 4, 3631 (2013).

${ }^{49}$ F. Lanucara, D. Scuderi, B. Chiavarino, S. Fornarini, P. Maitre, and M. E. Crestoni, J. Phys. Chem. Lett. 4, 2414 (2013).

${ }^{50}$ J. C. Molano-Arevalo, W. Gonzalez, K. Jeanne Dit Fouque, J. Miksovska, P. Maitre, and F. Fernandez-Lima, Phys. Chem. Chem. Phys. 20, 7043 (2018).

${ }^{51}$ P. B. Armentrout, Int. J. Mass Spectrom. 227, 289 (2003).

${ }^{52}$ G. Bouchoux, J.-Y. Salpin, and D. Leblanc, Int. J. Mass Spectrom. Ion Processes 153, 37 (1996).

${ }^{53}$ A. De Petris, M. E. Crestoni, A. Pirolli, C. Rovira, J. Iglesias-Fernández, B. Chiavarino, R. Ragno, and S. Fornarini, Polyhedron 90, 245 (2015).

${ }^{54}$ J. Lemaire, P. Boissel, M. Heninger, G. Mauclaire, G. Bellec, H. Mestdagh, A. Simon, S. Le Caer, J. M. Ortega, F. Glotin, and P. Maitre, Phys. Rev. Lett. 89, 273002 (2002).

${ }^{55}$ J. M. Bakker, T. Besson, J. Lemair, D. Scuderi, and P. Maitre, J. Phys. Chem. A 111, 13415 (2007).

${ }^{56}$ B. Chiavarino, M. E. Crestoni, S. Fornarini, S. Taioli, I. Mancini, and P. Tosi, J. Chem. Phys. 137, 024307 (2012).

${ }^{57}$ J. S. Prell, J. T. O’Brien, and E. R. Williams, J. Am. Soc. Mass Spectrom. 21, 800 (2010).

${ }^{58}$ Spartan 16, Program for Calculation of Molecular Properties, Wavefunction, Inc., Irvine, CA, USA, (2016).

${ }^{59}$ K. Balasubramanian, J. Agric. Food Chem. 54, 3512 (2006).
${ }^{60}$ R. Benassi, E. Ferrari, S. Lazzari, F. Spagnolo, and M. Saladini, J. Mol. Struct. 892, 168 (2008).

${ }^{61}$ K. Balasubramanian, Int. J. Quantum Chem. 116, 1107 (2016).

${ }^{62}$ M. K. Kesharwani, B. Brauer, and J. M. L. Martin, J. Phys. Chem. A 119, 1701 (2015).

${ }^{63}$ M. Elstner, D. Porezag, G. Jungnickel, J. Elsner, M. Haugk, T. Frauenheim, S. Suhai, and G. Seifert, Phys. Rev. B 58, 7260 (1998).

${ }^{64}$ M. Gaus, A. Goez, and M. Elstner, J. Chem. Theory Comput. 9, 338 (2013).

${ }^{65} \mathrm{M}$. Gaus, A. Goez, and M. Elstner, J. Chem. Theory Comput. 10, 1518 (2014).

${ }^{66}$ Y. Yang, H. Yu, D. York, Q. Cui, and M. Elstner, J. Phys. Chem. A 111, 10861 (2007).

${ }^{67}$ S. Grimme, J. Antony, S. Ehrlich, and H. Krieg, J. Chem. Phys. 132, 154104 (2010).

${ }^{68}$ B. Aradi, B. Hourahine, and Th. Frauenheim, J. Phys. Chem. A 111, 5678 (2007).

${ }^{69}$ M. Brehm and B. Kirchner, J. Chem. Inf. Model. 51, 2007 (2011).

${ }^{70}$ M. Borsari, E. Ferrari, R. Grandi, and M. Saladini, Inorg. Chim. Acta 328, 61 (2002).

${ }^{71}$ X.-Z. Zhao, T. Jiang, L. Wang, H. Yang, S. Zhang, and P. Zhou, J. Mol. Struct. 984, 316 (2010).

${ }^{72}$ M. H. M. Leung, D.-T. Pham, S. F. Lincoln, and T. W. Kee, Phys. Chem. Chem. Phys. 14, 13580 (2012).

${ }^{73}$ N. C. Polfer, J. Oomens, D. T. Moore, G. von Helden, G. Meijer, and R. C. Dunbar, J. Am. Chem. Soc. 128, 517 (2006).

${ }^{74}$ M. B. Burt, S. G. A. Decker, C. G. Atkins, M. Rowsell, A. Peremans, and T. D. Fridgen, J. Phys. Chem. B 115, 11506 (2011).

${ }^{75}$ A. Gholami and T. D. Fridgen, J. Phys. Chem. B 117, 8447 (2013).

${ }^{76} \mathrm{~A}$. M. Rijs and J. Oomens, Gas-phase IR Spectroscopy and Structure of Biological Molecules (Springer International Publishing Switzerland, 2015).

${ }^{77}$ T. M. Kolev, E. A. Velcheva, B. A. Stamboliyska, and M. Spiteller, Int. J. Quantum Chem. 102, 1069 (2005).

${ }^{78}$ L. Shen and H.-F. Ji, Spectrochim. Acta, Part A 67, 619 (2007).

${ }^{79}$ K. I. Priyadarsini, Molecules 19, 20091 (2014).

${ }^{80}$ A. L. Patrick, A. P. Cismesia, L. F. Tesler, and N. C. Polfer, Int. J. Mass Spectrom. 418, 148 (2017).

${ }^{81}$ R. K. Sinha, B. Chiavarino, M. E. Crestoni, D. Scuderi, and S. Fornarini, Int. J. Mass Spectrom. 308, 209 (2011).

${ }^{82}$ T. Kaweetirawatt, T. Yamaguchi, T. Higashiyama, M. Sumimoto, and K. Hori, J. Phys. Org. Chem. 25, 1097 (2012).

${ }^{83}$ M. Eigen, Angew. Chem., Int. Ed. Engl. 3, 1 (1964).

${ }^{84}$ C. F. Bernasconi, Pure Appl. Chem. 54, 2335 (1982).

${ }^{85}$ Y. Zhu, H. A. Roy, N. A. Cunningham, S. F. Strobehn, J. Gao, M. U. Munshi, G. Berden, J. Oomens, and M. T. Rodgers, J. Am. Soc. Mass Spectrom. 28, 2423 (2017).

${ }^{86}$ A. Zehnacker, Int. Rev. Phys. Chem. 33, 151 (2014).

${ }^{87}$ L. Voronina and T. R. Rizzo, Phys. Chem. Chem. Phys. 17, 25828 (2015).

${ }^{88}$ W. S. Hopkins, R. A. Marta, V. Steinmetz, and T. B. McMahon, Phys. Chem. Chem. Phys. 17, 28548 (2015).

${ }^{89}$ N. S. Nagornova, M. Guglielmi, M. Doemer, I. Tavernelli, U. Rothlisberger, T. R. Rizzo, and O. V. Boyarkin, Angew. Chem., Int. Ed. 50, 5383 (2011).

${ }^{90}$ J. Oomens, J. D. Steill, and B. Redlich, J. Am. Chem. Soc. 131, 4310 (2009).

${ }^{91}$ D. Scuderi, E. Bodo, B. Chiavarino, S. Fornarini, and M. E. Crestoni, Chem.Eur. J. 22, 17239 (2016). 